University of Nebraska - Lincoln DigitalCommons@University of Nebraska - Lincoln

Papers in Natural Resources

Natural Resources, School of

$10-1-2012$

\title{
AMO- and ENSO-Driven Summertime Circulation and Precipitation Variations in North America
}

Q. Steven $\mathrm{Hu}$

University of Nebraska - Lincoln, qhu2@unl.edu

Song Feng

University of Nebraska - Lincoln, sfeng2@unl.edu

Follow this and additional works at: http://digitalcommons.unl.edu/natrespapers

$\mathrm{Hu}, \mathrm{Q}$. Steven and Feng, Song, "AMO- and ENSO-Driven Summertime Circulation and Precipitation Variations in North America" (2012). Papers in Natural Resources. 387.

http://digitalcommons.unl.edu/natrespapers/387

This Article is brought to you for free and open access by the Natural Resources, School of at DigitalCommons@University of Nebraska - Lincoln. It has been accepted for inclusion in Papers in Natural Resources by an authorized administrator of DigitalCommons@University of Nebraska - Lincoln. 


\title{
AMO- and ENSO-Driven Summertime Circulation and Precipitation Variations in North America
}

\author{
QI HU AND SONG FENG \\ School of Natural Resources, and Department of Earth and Atmospheric Sciences, University of Nebraska \\ at Lincoln, Lincoln, Nebraska
}

(Manuscript received 13 September 2011, in final form 24 February 2012)

\begin{abstract}
Interannual and multidecadal time-scale anomalies in sea surface temperatures (SST) of the North Atlantic and North Pacific Oceans could result in persistent atmospheric circulation and regional precipitation anomalies for years to decades. Understanding the processes that connect such SST forcings with circulation and precipitation anomalies is thus important for understanding climate variations and for improving predictions at interannual-decadal time scales. This study focuses on the interrelationship between the Atlantic multidecadal oscillation (AMO) and El Niño-Southern Oscillation (ENSO) and their resulting interannual to multidecadal time-scale variations in summertime precipitation in North America. Major results show that the ENSO forcing can strongly modify the atmospheric circulation variations driven by the AMO. Moreover, these modifications differ considerably between the subtropics and the mid- and high-latitude regions. In the subtropics, ENSO-driven variations in precipitation are fairly uniform across longitudes so ENSO effects only add interannual variations to the amplitude of the precipitation anomaly pattern driven by the AMO. In the midand high latitudes, ENSO-forced waves in the atmosphere strongly modify the circulation anomalies driven by the AMO, resulting in distinctive interannual variations following the ENSO cycle. The role of the AMO is shown by an asymmetry in precipitation during ENSO between the warm and cold phases of the AMO. These results extend the outcomes of the studies of the recent Climate Variability and Predictability (CLIVAR) Drought Working Group from the AMO and ENSO effects on droughts to understanding of the mechanisms and causal processes connecting the individual and combined SST forcing of the AMO and ENSO with the interannual and multidecadal variations in summertime precipitation and droughts in North America.
\end{abstract}

\section{Introduction}

Interannual to decadal time-scale variations in sea surface temperatures (SST) of the world oceans provide boundary forcing that can initiate and sustain particular circulation anomalies in the atmosphere at the corresponding time scales. Many studies have examined how such SST variations may have developed and what roles the atmosphere and its interactions with the oceans have played in development of the SST variations (e.g., Namias 1959, 1965, 1969; Namias et al. 1988; Bjerknes 1964; Frankignoul 1985; Lau and Nath 1994, 1996; Latif and Barnett 1994; Seager et al. 2000; Kushnir et al. 2002). Investigations of atmospheric responses to these SST variations/forcings also have improved our understanding of effects of the SST variations on atmospheric

Corresponding author address: Dr. Qi Hu, 707 Hardin Hall, University of Nebraska at Lincoln, Lincoln, NE 68583-0987.

E-mail: qhu2@unl.edu processes and regional climate (e.g., Palmer and Sun 1985; Ting and Peng 1995; Trenberth et al. 1998; Venzke et al. 1999; Hu et al. 2011). These improvements have resulted in better predictions of interannual to multidecadal time scale variations in the atmosphere from regional to global scales (e.g., Latif and Barnett 1996; Griffies and Bryan 1997; Meehl et al. 2009).

The Atlantic multidecadal oscillation (AMO) is a prominent decadal time-scale SST variation (Mestas-Nunez and Enfield 1999; Kerr 2000). The AMO describes a North Atlantic basin-wide SST alternation between aboveand below-average SST anomalies over a period of 60 80 years (Enfield et al. 2001). Corresponding to the SST variations during the $\mathrm{AMO}$ are atmospheric circulation anomalies, particularly strong in the boreal summer over Europe and North America (Sutton and Hodson 2005, 2007; Wang et al. 2006; Hu and Feng 2008; Curtis 2008; Schubert et al. 2009; Mo et al. 2009; Hu et al. 2011; Feng et al. 2011). During the cold phase of the AMO the atmospheric circulation anomalies favor above-average 
precipitation in most of the contiguous United States, except for the north of the Northern Great Plains and the southeastern United States. On the other hand, during the warm phase of the AMO the corresponding circulation anomalies cause drier conditions across the United States, particularly severe in the central and southern Great Plains (e.g., Texas). These atmospheric circulation anomalies and associated summertime precipitation patterns driven by the AMO evolve and persist at the multidecadal time scale and have served as a strong component of the observed variations in circulation and precipitation in North America (Hurrell 1995; McCabe et al. 2004).

Other components contributing to the observed North American summertime precipitation variations at interannual to decadal time scales include those forced by the El Niño-Southern Oscillation (ENSO) and the Pacific decadal oscillation (PDO) (e.g., Lau 1985; Trenberth and Branstator 1992; Lau and Nath 1994; Trenberth and Guillemot 1996; Ting and Wang 1997; Hu and Feng 2001). These forcings have different time scales and different phases in both time and space from that of the AMO (Hu and Feng 2008). They cause atmospheric circulation variations that interact with those caused by the AMO. Because these interactions will ultimately determine the interannual and decadal time-scale precipitation variations in North America it is essential to understand interactions of the variations resulting from these forcings so that we may better understand and predict North American precipitation variation at interannual to decadal time scales.

Recently, the U.S. Climate Variability and Predictability (CLIVAR) Drought Working Group, a multiagency collaboration among the National Aeronautics and Space Administration (NASA), the National Oceanic and Atmospheric Administration (NOAA), the National Center for Atmospheric Research (NCAR), and U.S. university communities, organized an effort to facilitate understanding of the SST forcings associated with the AMO and ENSO on development of severe droughts in North America (Schubert et al. 2009). A group of six general circulation models (GCMs) were used to describe responses of the atmospheric circulations to the AMO and ENSO forcings and development of conditions for North American droughts. Results from these modeling studies have shown consistent AMO effects on droughts in North America (Schubert et al. 2009; Mo et al. 2009; Kushnir et al. 2010; also see a summary in Hu et al. 2011). These studies showed that the AMO effect on interannual variations of annual precipitation in North America is much weaker than that from the ENSO, suggesting ENSO as the dominant force for the interannual variations in precipitation and droughts. It is not surprising that the AMO has a weaker effect than ENSO on the annual precipitation in North America because the AMO affects primarily the summertime precipitation in North America (Sutton and Hodson 2007; Hu and Feng 2008; Feng et al. 2011). When such an effect is averaged on the annual scale it becomes weaker. On the other hand, the ENSO has persistent effects in different seasons, though strongest in boreal winter, so it has a strong effect on variations in annual precipitation. An indication that the AMO interacts with ENSO and influences North American summertime precipitation is that the AMO effect on the precipitation strengthened (weakened) when El Niño (La Niña) occurred (e.g., Lu and Dong 2005; Kitzberger et al. 2007; Mo et al. 2009; Nigam et al. 2011). These results suggest that ENSO effect on North American precipitation changes in different phases of the AMO or AMO induces multidecadal variations in the ENSO effect. While these studies have described the outcomes of the AMO and ENSO forcing on North American droughts there is little investigation of processes connecting the variations in North American summertime precipitation with the AMO and ENSO forcing. Thus, the questions of how the droughts develop or are favored in certain years/ decades and what are the major physical processes connecting the AMO and ENSO forcing to the North American summertime precipitation variations and drought development remain to be answered.

In this study, we address these questions by examining the physical processes and joint impacts of the AMO and ENSO. We built this study using the results described in $\mathrm{Hu}$ et al. (2011) and on the current understanding of AMOforced circulation and precipitation variations. The NCAR Community Atmosphere Model, version 3 (CAM3) model was used in this study. Results of model experiments are compared and contrasted to identify the physical processes of the AMO and ENSO and their individual and joint impacts on summertime circulation and precipitation variations in North America. Results of this study will help develop the framework, when the PDO effects and local land surface feedbacks are added, for understanding and improving predictions of North American summertime precipitation variations from interannual to multidecadal time scales. The model and simulation procedures are described in the next section (section 2). Results of the simulations and the AMO-ENSO interrelationship and impacts described in these results are discussed in section 3. Major conclusions of this study are summarized in section 4 .

\section{Model and experiments}

\section{a. Model}

As in $\mathrm{Hu}$ et al. (2011), we used the CAM version 3.1 (Collins et al. 2006), developed at the NCAR. Ideally, 
multiple models should be used in such simulations to avoid possible individual model bias. We used the CAM model because our previous studies have shown that this model captures the observed precipitation variations related to the SST forcing in the North Atlantic and North Pacific (Hu et al. 2011). In addition, the model simulations are consistent with those from other models (e.g., Feng et al. 2011; Schubert et al. 2009; Mo et al. 2009). It is thus adequate to use this model when the focus is to study physical processes-mechanisms causing the interested variations (in contrast to mean values of simulated-predicted temperature and precipitation). Another reason for using the CAM model is because it was used in the study of Hu et al. (2011) and this current study is a follow up to that previous study. Details of the CAM3.1 model and model settings are the same as those described in $\mathrm{Hu}$ et al. (2011) and are not repeated here. Model experiments for this study are described in the following.

\section{b. Model experiments}

Model experiments were designed to identify and quantify effects of SST anomalies in the equatorial Pacific and the North Atlantic Oceans on summertime atmospheric circulation and precipitation in North America. The SST data were obtained from the merged monthly mean U.K. Hadley Centre sea ice and SST dataset version 1 (HadISST1) and version 2 of the U.S. NOAA weekly optimum interpolation SST analysis (Hurrell et al. 2008). The spatial resolution of the data is $1.0^{\circ} \times$ $1.0^{\circ}$ in latitude and longitude. The control run used the monthly global climatological SST field averaged over the period from 1871 to 2008 . The same monthly global climatological SST was used for every year in the 50-yr control run. Results of the control run were used as the reference by which we quantified the forcing of the tropical Pacific and North Atlantic SST anomalies on circulation and precipitation in North America.

For the AMO-driven circulation and precipitation, we conducted two experimental runs with contrasting SST anomalies imposed in the North Atlantic Ocean designed to represent the warm and cold phases of the AMO. Climatological SSTs were imposed elsewhere in the world oceans. These experiments are denoted as $A_{w} P_{n}$ and $A_{c} P_{n}$, where $P_{n}$ indicates climatological (normal) SST in the equatorial Pacific Ocean. Detailed procedures for developing the SST anomalies representing the warm (cold) phases of the AMO have been described in Hu et al. (2011). The derived SST anomaly fields in the North Atlantic Ocean for the AMO warm and cold phases are shown in Hu et al. (2011, see their Fig. 1). These experimental runs have been completed and reported in Hu et al. (2011), and their results were directly used in this study.
For the ENSO-forced circulation and precipitation variations, we made two experimental runs with contrasting SST anomalies imposed in the equatorial Pacific Ocean to represent the El Niño and La Niña conditions. Climatological SSTs were imposed elsewhere in the world oceans. These experiments are denoted as $\mathrm{A}_{\mathrm{n}} \mathrm{P}_{\mathrm{w}}$ and $\mathrm{A}_{\mathrm{n}} \mathrm{P}_{\mathrm{c}}$ for climatological SST in the North Atlantic and warm and cold anomalies in the equatorial Pacific Ocean, respectively. To develop the SST anomalies representing El Niño and La Niña, we first identified those years that had the annual Niño-3.4 SST (averaged SST in $120^{\circ}-170^{\circ} \mathrm{W}$ and $5^{\circ} \mathrm{S}-5^{\circ} \mathrm{N}$ ) in the warmest (coldest) $25 \%$ (quartile) for the period 1871-2008. We then calculated corresponding monthly SST anomalies during those warmest (coldest) $25 \%$ years from the mean of 1871-2008 at each model grid point in the tropical Pacific Ocean. The derived summer [June, July, and August (JJA)] SST anomaly fields in the equatorial Pacific for the warm (El Niño) and cold (La Niña) phases of the ENSO cycle shown in Figs. 1a and 1b, respectively, were used in these experiments. These SST anomalies differ from those used in U.S. CLIVAR drought working group (Schubert et al. 2009), which were derived based on the EOF of the annual SST over the global oceans.

Four additional experimental runs were conducted with SST anomalies in both the North Atlantic Ocean and the equatorial Pacific Ocean to represent concurrent forcings of the AMO and ENSO. Among the four, two experiments had opposite SST anomalies in the equatorial Pacific Ocean but positive SST anomalies in the North Atlantic Ocean. These experiments represent the El Niño and La Niña conditions in the equatorial Pacific during the warm phase of the AMO. They are denoted as $\mathrm{A}_{w} \mathrm{P}_{w}$ and $\mathrm{A}_{w} \mathrm{P}_{c}$, respectively. The other two experiments had opposite SST anomalies in the equatorial Pacific Ocean but negative SST anomalies in the North Atlantic Ocean. These two experiments describe the El Niño and La Niña conditions in the equatorial Pacific during the cold phase of the AMO and are denoted as $\mathrm{A}_{\mathrm{c}} \mathrm{P}_{\mathrm{w}}$ and $\mathrm{A}_{\mathrm{c}} \mathrm{P}_{\mathrm{c}}$, respectively.

In all these experiments, the SST anomalies in either the equatorial Pacific Ocean or the North Atlantic Ocean, or both as in $\mathrm{A}_{w} \mathrm{P}_{w}, \mathrm{~A}_{w} \mathrm{P}_{c}, \mathrm{~A}_{c} \mathrm{P}_{\mathrm{w}}$, and $\mathrm{A}_{c} \mathrm{P}_{c}$, were imposed in every month and year of the model run, and the CAM3.1 was integrated for 50 years. Because the other model parameters in the experiments were the same as in the control run, differences between the experiments and the control run and among the experiments will show summertime circulation and precipitation anomalies driven by the ENSO cycle or the AMO or their concurrent SST anomalies. In this study, we analyzed the differences between the model years 7-20 in 

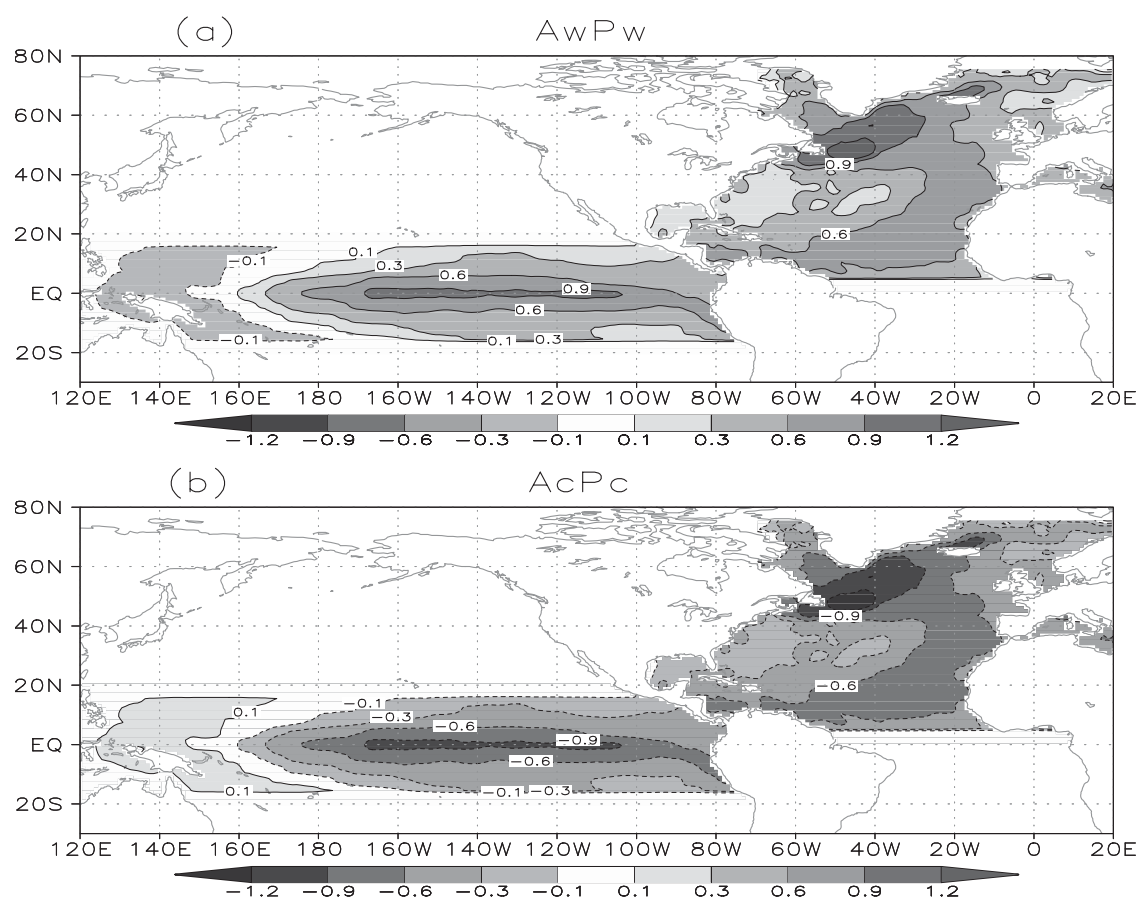

FIG. 1. (a) The SST anomalies (K) in the North Atlantic Ocean for the warm phase of the AMO and the SST anomalies in the equatorial Pacific Ocean for El Niño $\left(A_{w} P_{w}\right)$. (b) As in (a), but for cold phase of the AMO and La Niña $\left(\mathrm{A}_{c} \mathrm{P}_{c}\right)$. Different combinations of these SST anomalies in the North Atlantic and the equatorial Pacific Oceans are used in other model experiments.

the experimental runs, after removing the first six years for spinup, and the 50-yr control run. As described in Hu et al. (2011), comparisons between the averaged 720 and 50-yr control run results showed few differences in both the mean and variance of seasonal circulation (geopotential height and winds) and precipitation; statistical tests identified no significant differences between these results. These test results were such that we felt they warranted the use of the 20 -yr simulations in our analyses.

\section{Results}

\section{a. Lower-troposphere circulation}

We examined the interrelationship and impacts of the AMO and ENSO from outputs of the model control run and experiments of AMO-only runs $\left(\mathrm{A}_{\mathrm{w}} \mathrm{P}_{\mathrm{n}}\right.$ and $\left.\mathrm{A}_{\mathrm{c}} \mathrm{P}_{\mathrm{n}}\right)$, ENSO-only runs $\left(\mathrm{A}_{n} \mathrm{P}_{\mathrm{w}}\right.$ and $\left.\mathrm{A}_{n} \mathrm{P}_{c}\right)$, and concurrent AMO-ENSO runs $\left(\mathrm{A}_{\mathrm{w}} \mathrm{P}_{\mathrm{w}}, \mathrm{A}_{\mathrm{w}} \mathrm{P}_{\mathrm{c}}, \mathrm{A}_{\mathrm{c}} \mathrm{P}_{\mathrm{w}}\right.$, and $\left.\mathrm{A}_{\mathrm{c}} \mathrm{P}_{\mathrm{c}}\right)$. Results of $A_{w} P_{n}$ and $A_{c} P_{n}$ are from Hu et al. (2011). The AMO-ENSO runs described a "snapshot" of interannual SST variations in the equatorial Pacific associated with ENSO in a background SST anomaly, warm or cold, in the North Atlantic associated with the AMO.
Figure 2 shows the simulated average summertime sea level pressure (SLP) from the ENSO-only runs. For reference, Figs. 2a shows the SLP from the control run with climatological SST in all oceans. Results in Figs. 2b and $2 \mathrm{c}$ show the averaged JJA SLP anomalies corresponding to El Niño and La Niña in the equatorial Pacific (Fig. 1), respectively. ${ }^{1}$ During El Niño (Fig. 2b), the warming SST in the central and eastern equatorial and subtropical North Pacific caused a weakening of the North Pacific subtropical high pressure system (NPSH). Negative SLP anomalies are shown in the central and eastern equatorial Pacific and most of the North Pacific. Meanwhile, the SLP over North America shows positive anomalies. These positive SLP anomalies are attributable to the weakening of the NPSH and reduced mass outflow from the land to the eastern North Pacific. The result also shows that the warming in the equatorial

\footnotetext{
${ }^{1}$ In Figs. $2 b$ and 2c, the areas of SLP anomalies that are significantly different (at the $95 \%$ confidence level) from the control run result in Fig. 2a match the anomaly areas shaded in Fig. 2d, where significant differences in anomalies of the SLP also occurred between the warm and cold phase of the ENSO cycle. These areas are not highlighted in Figs. $2 b$ and $2 c$ to preserve their readability. Similar results appeared in Figs. 3-8.
} 
(a) JJA SLP (Control Run)

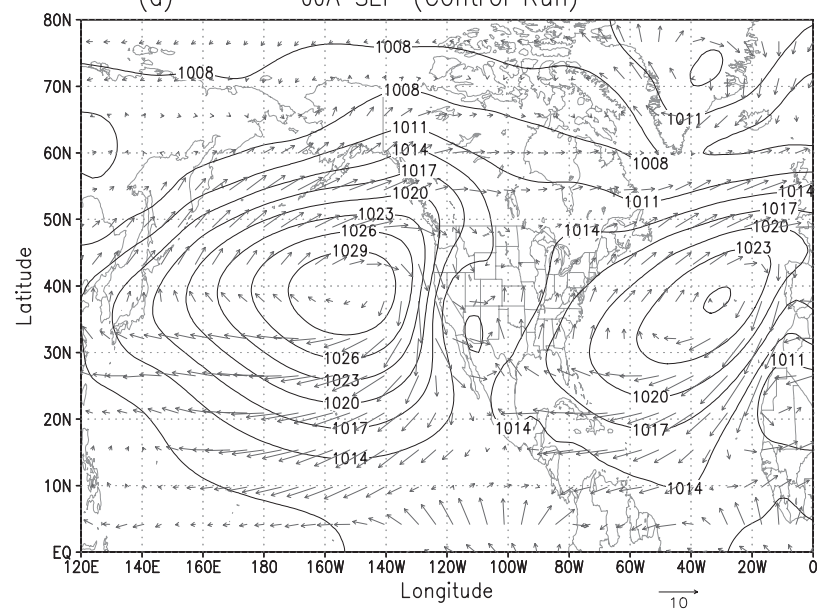

(c) JJA SLP (AnPc)

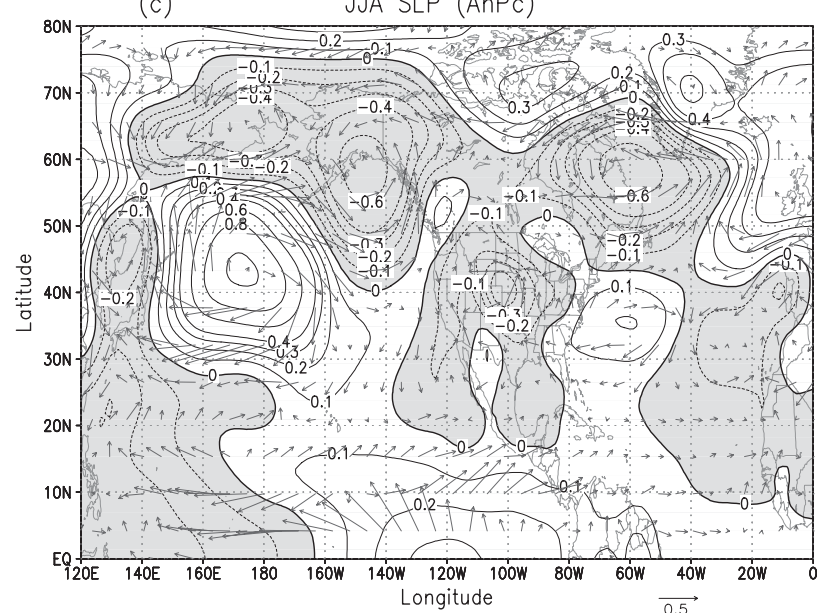

(b)

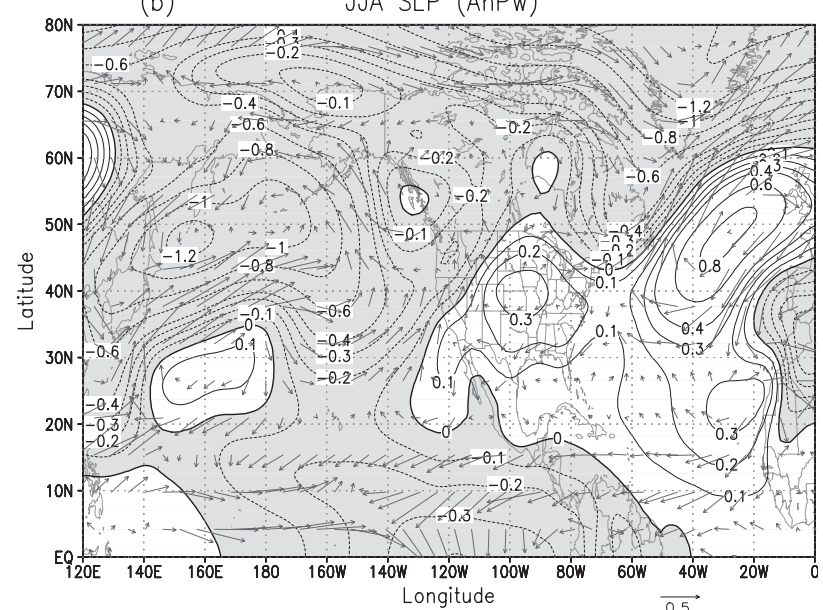

(d)

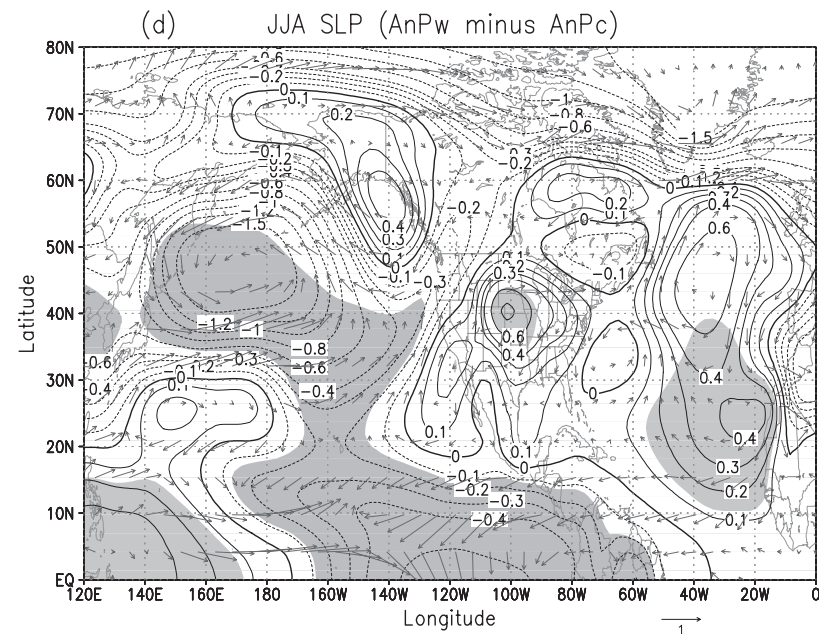

FIG. 2. (a) Modeled sea level pressure (SLP; 100 pa) for control run. (b),(c) SLP anomalies averaged for ENSO warm ( $\left.A_{n} P_{w}\right)$ and cold phase $\left(A_{n} P_{c}\right)$, respectively (negative anomalies are shaded). (d) Differences between (b) and (c). The arrows in the panels show the surface wind (and wind difference in Fig. $2 \mathrm{~d})\left(\mathrm{m} \mathrm{s}^{-1}\right)$. Shadings in (d) indicate that the differences in SLP anomalies are significant at the $95 \%$ confidence level by the two-tailed Student's $t$ test.

Pacific also enhances the North Atlantic subtropical high (NASH) and pushes the SLP center to slightly higher latitudes in the North Atlantic.

A nearly opposite SLP anomaly pattern emerges in Fig. 2c during La Niña. Colder SST anomalies in the eastern equatorial and subtropical Pacific enhanced the NPSH in the central and eastern North Pacific. The enhanced NPSH induces negative SLP anomalies in North America, in a reversed way to that previously discussed. The differences of the SLP anomalies between El Niño and La Niña are shown in Fig. 2d, marking three regions with significant contrast in SLP anomalies. These regions, shaded in Fig. 2d, are in the eastern equatorial Pacific and eastern and central North Pacific, the central United States, and the subtropical North Atlantic. As we will show next, the same pattern in difference of the SLP anomalies between the warm and cold phases of the ENSO cycle repeats in both warm and cold phases of the AMO.

In the warm phase of the AMO, negative SLP anomalies prevail in North America and the eastern North Pacific under both El Niño and La Niña conditions (Figs. 3a and 3b, note that the control run result is the same as that in Fig. 2a). Negative SLP anomalies also occur in the central and western North Atlantic. While the magnitudes and some regional features differ, the SLP anomaly pattern in both El Niño (Fig. 3a) and La Niña (Fig. 3b) are similar to that driven by the warm phase of the AMO alone (Fig. 3d). This similarity suggests that the AMO-driven anomalies in the warm phase determine the bulk features of the SLP anomalies in North America and over the oceans on both 

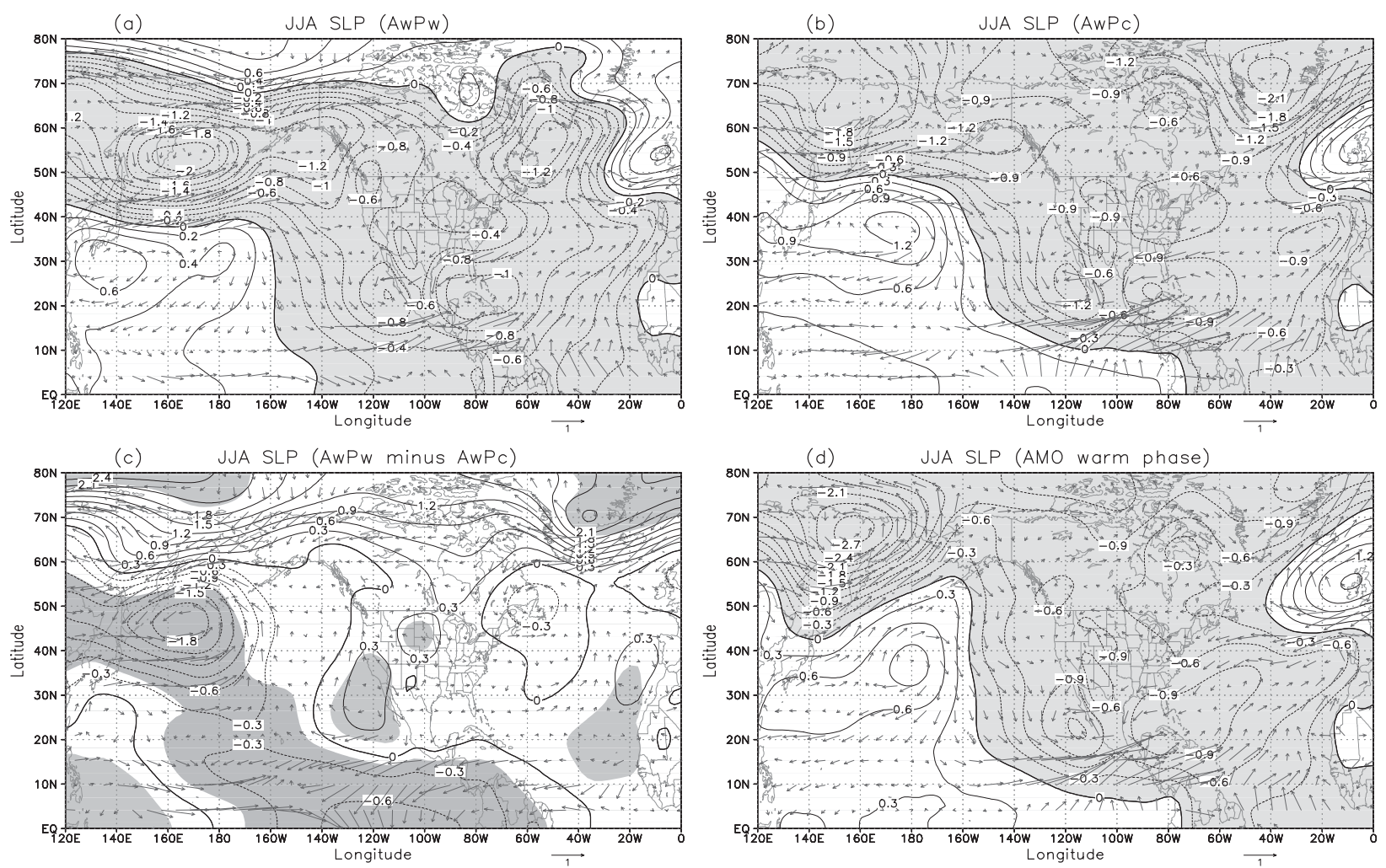

FIG. 3. Simulated impacts of (a) El Niño and (b) La Niña on SLP (100 pa) during warm phase of the AMO. (c) Differences between (a) and (b). For comparison, the modeled SLP anomalies in the warm phase of the AMO alone are shown in (d). Arrows in the panels show the surface wind or its difference $\left(\mathrm{m} \mathrm{s}^{-1}\right)$. Negative anomalies in (a),(b),(d) are shaded. Shadings in (c) indicate significant differences in SLP anomalies between (a) and (b) at the $95 \%$ confidence level by the two-tailed Student $t$-test.

sides. The effects of the SST forcing of El Niño and La Niña are superimposed on these AMO-driven anomalies and specify regional anomaly features. These effects can be shown by comparison and contrast differences of the SLP anomalies between the results in Figs. $3 a$ and $3 b$. These differences are shown in Fig. $3 \mathrm{c}$ and describe a pattern similar to that in Fig. $2 d$ with the same three regions having statistically significant contrasts in SLP anomaly between El Niño and La Niña.

The same results emerged in the model experiments for the cold phase of the AMO (Fig. 4). The SLP anomalies in the El Niño and La Niña conditions during the cold phase of the AMO are shown in Figs. 4a and 4b. They both show positive SLP anomalies in North America as well as in the North Atlantic, although the SLP anomalies in North America in La Niña have a smaller magnitude than that over the oceans surrounding the land area. Again, the SLP anomaly pattern in both Figs. $4 \mathrm{a}$ and $4 \mathrm{~b}$ is similar to that driven by the AMO cold phase alone (Fig. 4d). When the differences between anomalies in Figs. $4 \mathrm{a}$ and $4 \mathrm{~b}$ were calculated the results, shown in Fig. 4c, indicate a pattern similar to those shown in Figs. $3 \mathrm{c}$ and $2 \mathrm{~d}$.
The results above indicate that El Niño and La Niña are affecting the North Pacific and North America in a similar way in the cold, warm, and neutral phases of the AMO. Thus, it can be concluded that while the AMO sets background anomalies in the atmospheric mass and wind fields, or in the absence of AMO effect as in its neutral phase, the ENSO effects ride on the AMO-driven anomalies and influence the circulation in a nearly invariant way. These effects of ENSO are shown by the opposite wave patterns, particularly strong in the midlatitudes, between El Niño and La Niña in all phases of the AMO (Figs. 4c, 3c, and 2d).

Because the anomaly fields driven by the AMO differ between its warm and cold phases these results dictate that ENSO modify the AMO effect differently in different phases of the AMO. Modifications of ENSO on AMO effects are mainly shown in 1) changing the AMOinduced pressure anomalies in North America, and 2) limiting or extending the westward expansion of the AMO-induced SLP anomalies to the North and equatorial Pacific. In North America, as previously discussed for the ENSO-only cases, the effect of El Niño is to enhance high SLP in North America, and the effect of La Niña is 

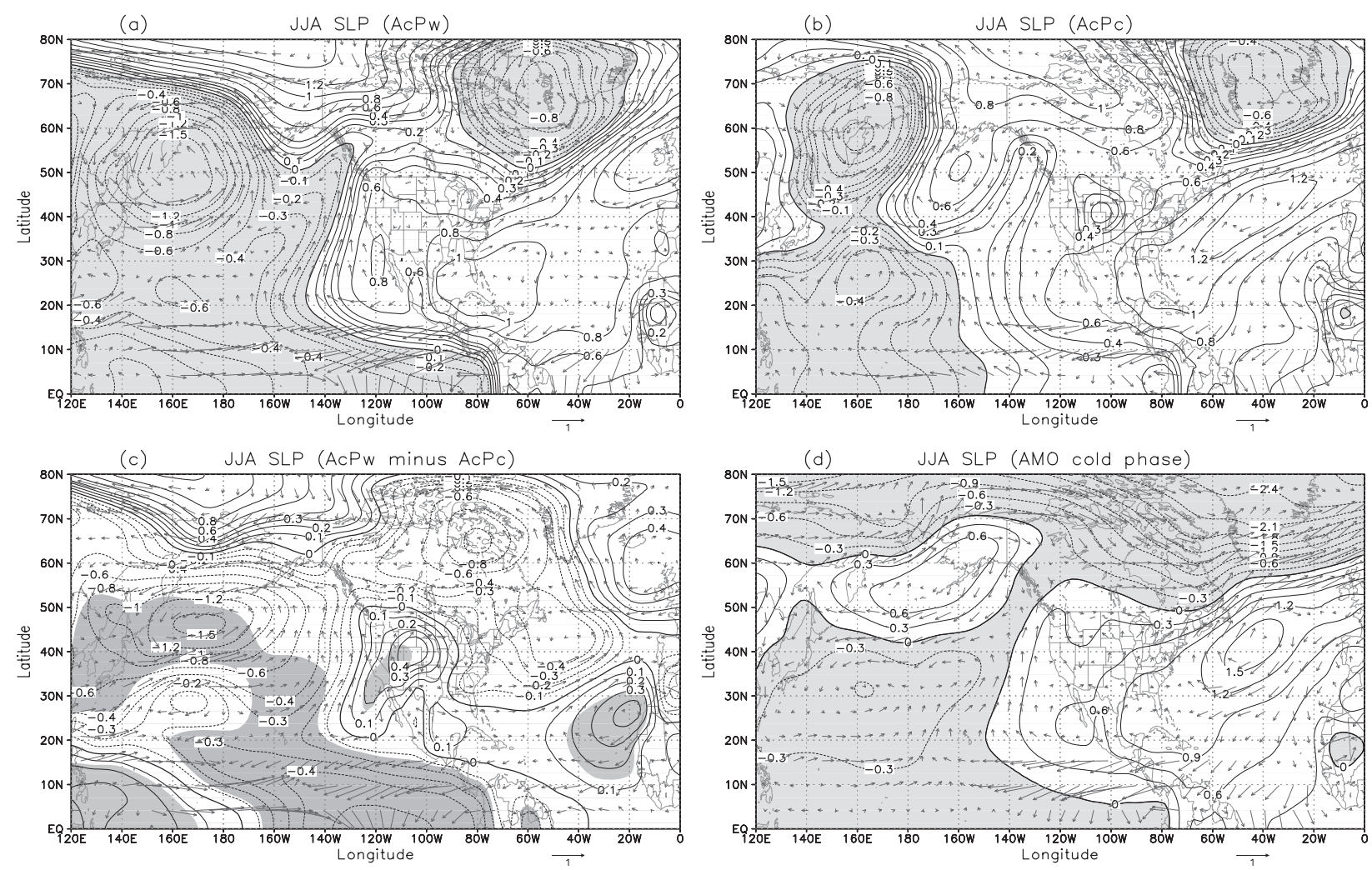

FIG. 4. As in Fig. 3, but during the cold phase of the AMO.

to enhance low SLP across the continent. When these effects are superimposed on the anomalies driven by the AMO, the negative SLP anomalies in North America in the warm phase of the AMO will be smaller during El Niño (Fig. 3a) than during La Niña (Fig. 3b). In the Pacific Ocean, during the AMO warm phase, El Niñoinduced warming of the eastern equatorial Pacific SST weakens the SLP in the eastern equatorial and subtropical Pacific (Fig. 3a). This effect of El Niño extends the AMO-induced negative SLP anomaly from North America into the eastern North Pacific and tropical Pacific. On the other hand, during La Niña, the cooling in the eastern equatorial Pacific SST enhances the SLP in the eastern equatorial and subtropical North Pacific. This effect of La Niña confines the negative SLP anomalies induced by the warm phase of the AMO to the east (Fig. 3b). This effect is particularly clearly shown in the tropical and subtropical North Pacific. These modulations on the SLP anomalies in North America by ENSO are summarized in Fig. 3c, which shows that the SLP is higher in North America during El Niño than in La Niña, and the SLP is lower in the equatorial and eastern and central North Pacific during an El Niño than in a La Niña.

In the AMO cold phase, AMO-driven positive SLP anomalies prevail in North America and the eastern
North Pacific (Fig. 4d). When El Niño occurs, its induced SST warming in the eastern equatorial Pacific weakens the eastern part of the NPSH and therefore curbs the positive SLP anomalies to regions east of $140^{\circ} \mathrm{W}$ longitude. West of this division, large negative SLP anomalies develop (Fig. 4a). When La Niña occurs, however, cooling of the eastern equatorial Pacific SST enhances the SLP in the eastern equatorial Pacific and subtropical North Pacific. This effect of La Niña extends the positive anomalies of the SLP induced by the cold phase of the AMO farther west (Fig. 4b). In North America, similar processes associated with the modifications of the NPSH by ENSO enhance the positive SLP anomalies during El Niño, but weaken the SLP in La Niña. As a result, the SLP shows enhanced positive anomalies in North America and in a small region in the subtropical eastern North Pacific during an El Niño (Fig. 4a), and much weaker yet wider spread, positive SLP anomalies from North America to near the date line during a La Niña (Fig. 4b). The differences between these anomalies in El Niño and in La Niña again show higher SLP in North America and lower SLP in the equatorial Pacific and eastern and central North Pacific during El Niño than in La Niña (Fig. 4c). Figure 4c has a very similar pattern to that in Fig. $3 \mathrm{c}$ and also Fig. $2 \mathrm{~d}$. 
Because Fig. 2d shows the differences in the neutral or absence of the AMO, these similarities indicate that ENSO forcing modifies the circulation anomalies driven by the AMO, in either its warm or its cold phase, in ways such that the net effect of ENSO on the SLP is nearly invariant with respect to the AMO.

Furthermore, the positive difference in North America shown in Figs. 4c, 3c, and 2 d indicates that the forcing of El Niño is always raising the SLP and the forcing induced by La Niña is lowering the SLP from the background anomalies in North America. Meanwhile, the negative difference in eastern equatorial Pacific and eastern and central North Pacific indicates that the forcing of El Niño is always lowering the SLP and the forcing of La Niña is enhancing the low-level pressure from the background anomalies in those areas. These consistent patterns of the forced anomalies by ENSO on lower-troposphere mass and wind fields regardless of the phases of the AMO suggest a linear superposition of the ENSO effect on the AMO-driven anomalous mass distribution. They indicate little evidence of strong nonlinear interrelationship between ENSO and the AMO. Should such a nonlinear interrelationship between ENSO and the AMO be at work, the SLP anomalies in response to El Niño or La Niña would have been rather different in different phases of the AMO. The patterns in Figs. $4 c, 3 c$, and $2 \mathrm{~d}$ would have had been different. This issue will be further elaborated.

\section{b. Upper troposphere}

The same conclusion for a linear interrelationship between ENSO and the AMO and their joint impacts can be drawn for the upper troposphere. As shown in Figs. 5-7, upper troposphere anomalies in mass and wind driven by El Niño are similar between cold or warm phases of the AMO. The same is also observed for La Niña. These anomalies show higher atmospheric pressure along the tropical and subtropical latitudes during an El Niño and lower pressure in those latitudes in a La Niña, regardless of the phases of the AMO. These consistent anomalies also result in the same pattern of pressure differences in those latitudes between El Niño and La Niña as shown in Figs. 5d, 6c, and 7c, which are analogous to Figs. $4 \mathrm{c}, 3 \mathrm{c}$, and $2 \mathrm{~d}$ for the lower troposphere.

In the midlatitude, pressure over the central and northern North Pacific is always lower during El Niño than in La Niña, in all phases of the AMO (Figs. 5d, 6c, and $7 \mathrm{c}$ ). This is consistent with the anomalies in the lower troposphere as required by mass conservation. In a reversed situation, the pressure is always slightly higher over most of North America during El Niño than in La Niña, thus resulting in weak positive pressure differences in the region between El Niño and La Niña
(Figs. 5d, 6c, and 7c). A negative pressure difference center, significant at the $95 \%$ confidence level, occurs in the eastern subtropical to midlatitude North Pacific in all phases of the AMO (between $120^{\circ}$ and $170^{\circ} \mathrm{W}$ longitude). Our analysis of the pressure and wind variations suggested that in that region the circulation anomaly between El Niño and La Niña in different phases of the AMO is closely associated with the circulation variations in the subtropical North America and different to that in the central North Pacific. This result may suggest disturbances excited from peak SST anomalies in the eastern tropical Pacific, associated with El Niño or La Niña, propagating meridionally to influence midlatitude North America.

\section{c. Circulation and precipitation}

Before discussing summertime precipitation variations caused by the ENSO and AMO forcings, we will discuss precipitation variations driven by ENSO alone. Figure 8a shows that El Niño causes above-average precipitation in the central United States and belowaverage precipitation in regions to its north and south. Figure $8 \mathrm{~b}$ shows a nearly reversed precipitation anomaly pattern caused by La Niña. Most notable are the slightly above-average precipitation in the southern tier of the United States and Mexico and the strong deficit in precipitation in the central and northern parts of North America. The difference of these precipitation anomalies, shown in Fig. 8c, clearly depicts the distinctively different effects of El Niño and La Niña on summertime precipitation in the central United States.

Because of the primarily linear superposition of the ENSO effects on the circulation anomalies associated with the AMO, the ENSO cycle largely influences the interannual summertime precipitation variation in North America and the subtropics. Furthermore, as shown in Figs. 8b-d, the ENSO effect has a stronger longitudinal variation in midlatitude North America than in the tropical and subtropical regions. In the latter (south of the $35^{\circ} \mathrm{N}$ latitude), ENSO forcing causes fairly uniform anomalies in pressure in both the lower- and upper-troposphere (Figs. 3-7). Particularly, across the broad region from $60^{\circ} \mathrm{W}$ to the date line, the tropical and subtropical regions have lower pressure in the lowertroposphere during El Niño and higher pressure during La Niña, regardless of the phases of the AMO (Figs. 3 and 4). Reversed anomalies are shown in the upper troposphere for El Niño or La Niña (Figs. 6 and 7). The difference of the pressure anomalies between El Niño and La Niña has the same sign across the region regardless the phases of the AMO (Figs. 6c and 7c). These spatially uniform anomalies in circulation driven by ENSO simply change the magnitude of the circulation 

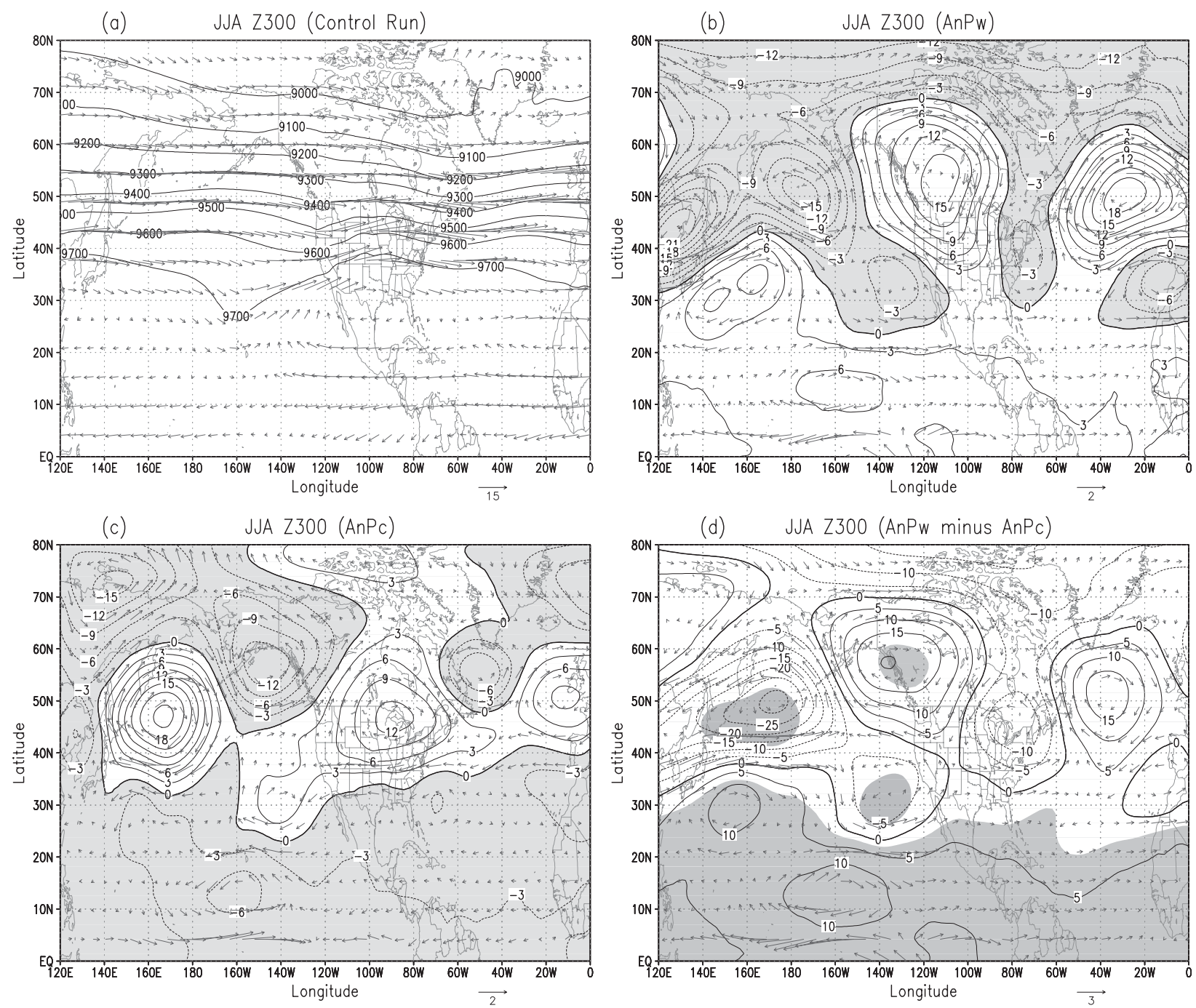

FIG. 5. (a) Simulated 300-hPa geopotential height $\left(\mathrm{m}^{2} \mathrm{~s}^{-2}\right.$ ) for control run. (b), (c) Anomalies from the control run averaged for ENSO warm $\left(A_{n} P_{w}\right)$ and cold phase $\left(A_{n} P_{c}\right)$, respectively (negative anomalies are shaded). (d) Differences between (b) and (c). Arrows in the panels show 300-hPa wind or its difference $\left(\mathrm{m} \mathrm{s}^{-1}\right)$. Shadings in (d) indicate the differences in geopotential height are significant at the $95 \%$ confidence level by the two-tailed Student's $t$ test.

anomalies driven by the AMO, adding little spatial variation to the AMO-driven anomalies. Consequently, the precipitation anomalies associated with such anomalies in circulation resemble a spatial distribution similar to that driven by the AMO, while the magnitude of the anomalies fluctuates at the interannual time scale similar to ENSO's. Quite differently, in midlatitude North America, the strong longitudinal variation in ENSO effect adds substantial regional variations to the AMO-driven anomalies in circulation and precipitation. Consequently, the summertime precipitation variations become more complex across midlatitude North America.

Figures $9 \mathrm{a}$ and $9 \mathrm{~b}$ show the summertime precipitation anomalies in El Niño and La Niña, respectively, during the warm phase of the AMO. Clearly, the anomaly patterns between these opposite conditions in the ENSO cycle are similar in the latitudes south of the $35^{\circ} \mathrm{N}$. These patterns are very similar to those forced by the SST anomalies in the warm phase of the AMO (Fig. 9c), but are very different from those shown in Figs. $8 \mathrm{~b}$ and $8 \mathrm{c}$ driven by ENSO alone. Between the anomalies in Figs. 9a and 9b, the primary difference is in the magnitude of precipitation anomalies. They are weak during El Niño and strong during La Niña, largely because of the superposition of enhanced negative precipitation anomaly during El Niño and an opposite effect during La Niña in those tropical and subtropical latitudes (see Figs. 8b and $8 \mathrm{c}$ ). 

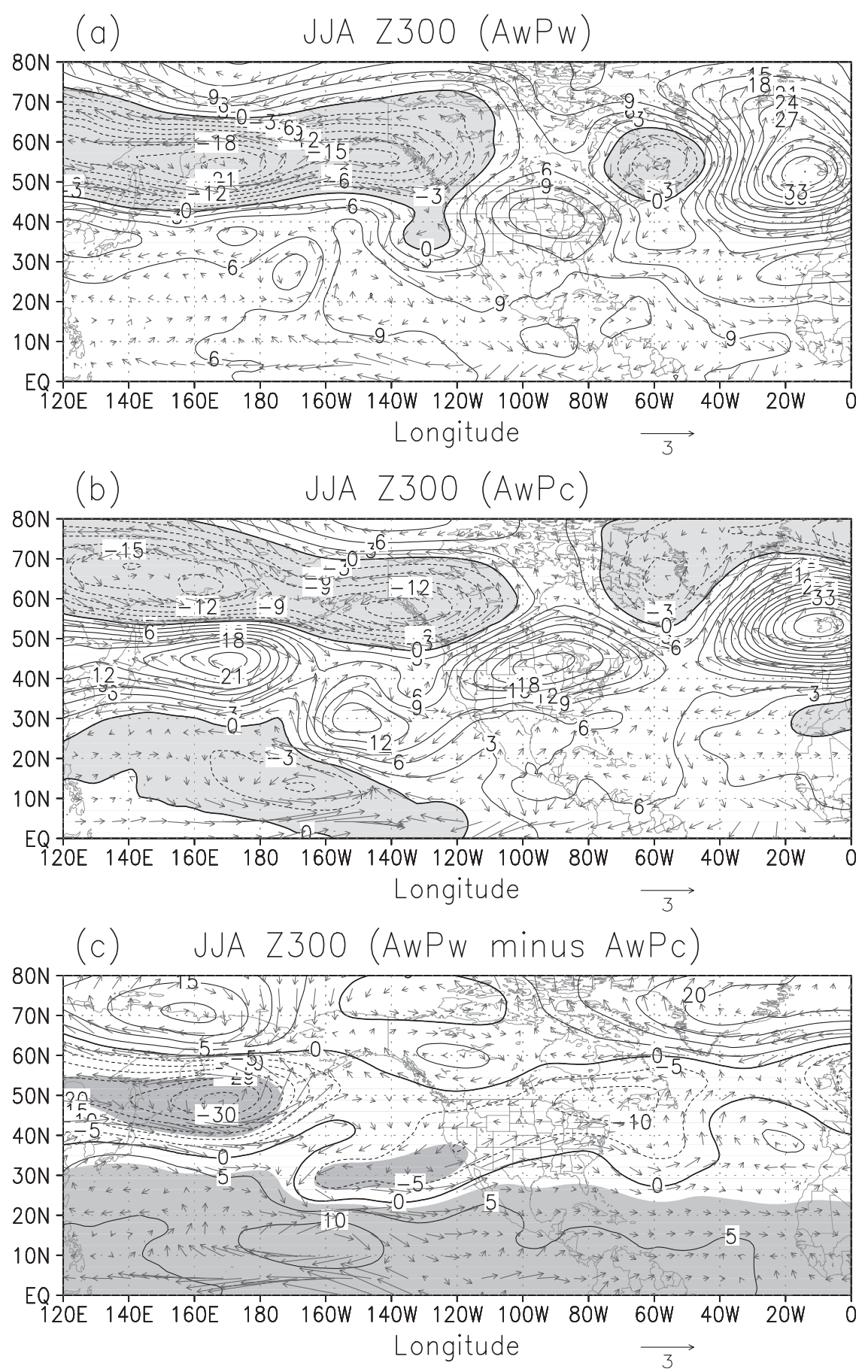

FIG. 6. Simulated impacts of (a) El Niño and (b) La Niña on 300-hPa geopotential height $\left(\mathrm{m}^{2} \mathrm{~s}^{-2}\right)$ during warm phase of the AMO (negative anomalies are shaded). (c) Differences between (a) and (b). Arrows in the panels show 300-hPa wind or its difference $\left(\mathrm{m} \mathrm{s}^{-1}\right)$. Shadings in (c) indicate significant differences in geopotential height at the $95 \%$ confidence level by the two-tailed Student $t$-test.

Similarly, as shown in Figs. 9d and 9e, the summertime precipitation anomalies in El Niño and La Niña during the cold phase of the AMO have the same pattern in regions south of $35^{\circ} \mathrm{N}$ latitude, similar to those driven by the AMO cold phase alone (Fig. 9f). Again, the major difference between these patterns is in the magnitude. And, as previously discussed, this magnitude difference is a reflection of the fairly evenly distributed ENSO 


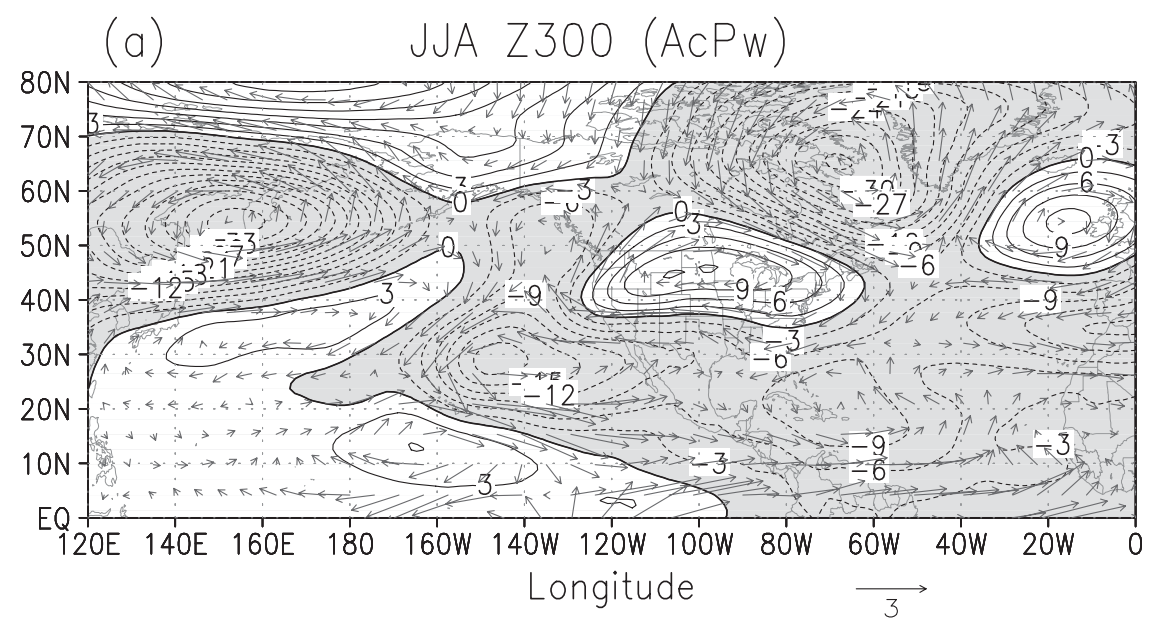

(b)

JJA Z300 (AcPc)

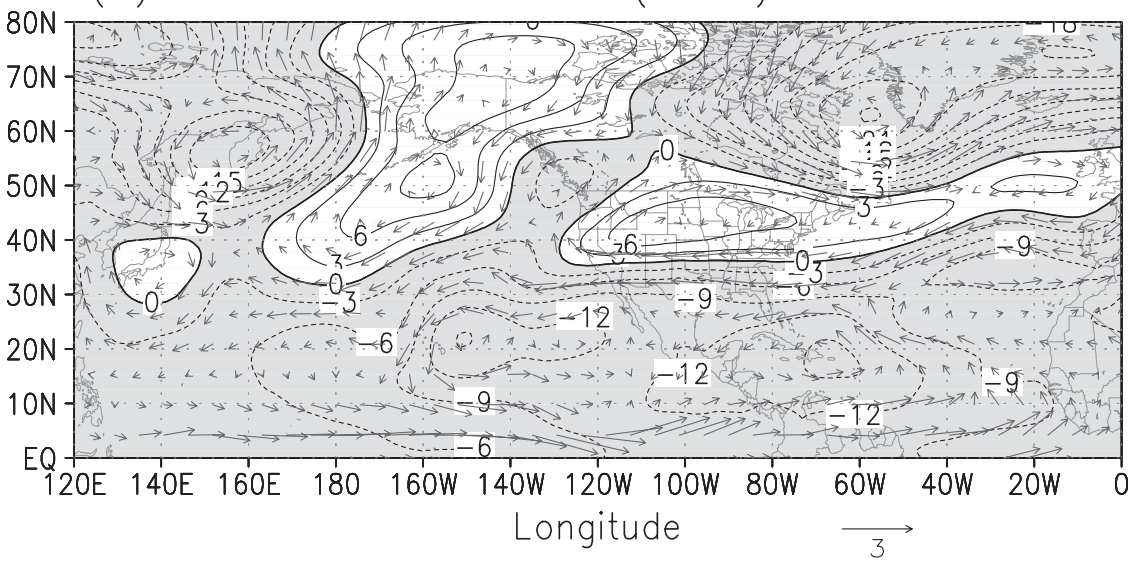

(c) JJA Z300 (AcPw minus AcPc)

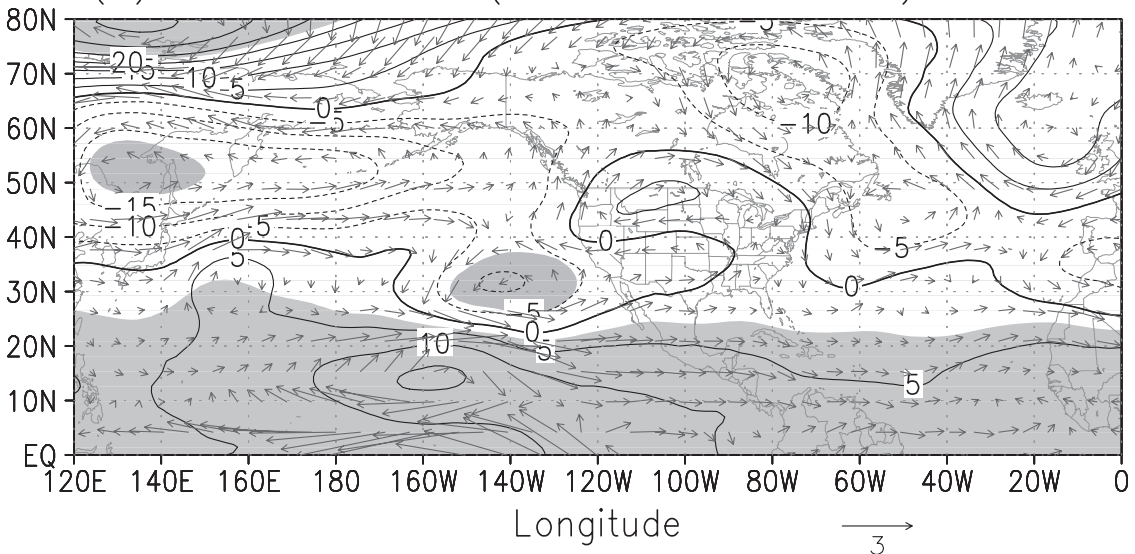

FIG. 7. As in Fig. 6, but for the cold phase of the AMO.

modifications of the AMO-driven precipitation anomalies in these latitudes.

This interrelationship between ENSO and the AMO changes considerably in midlatitude North America where, as previously discussed, ENSO has a strong role in determining regional features (across the latitude) in precipitation anomalies. This different relationship of the ENSO and the AMO in the midlatitude also is shown in Fig. 9. Figures 9a and 9b show quite opposite precipitation anomalies in midlatitude North America 

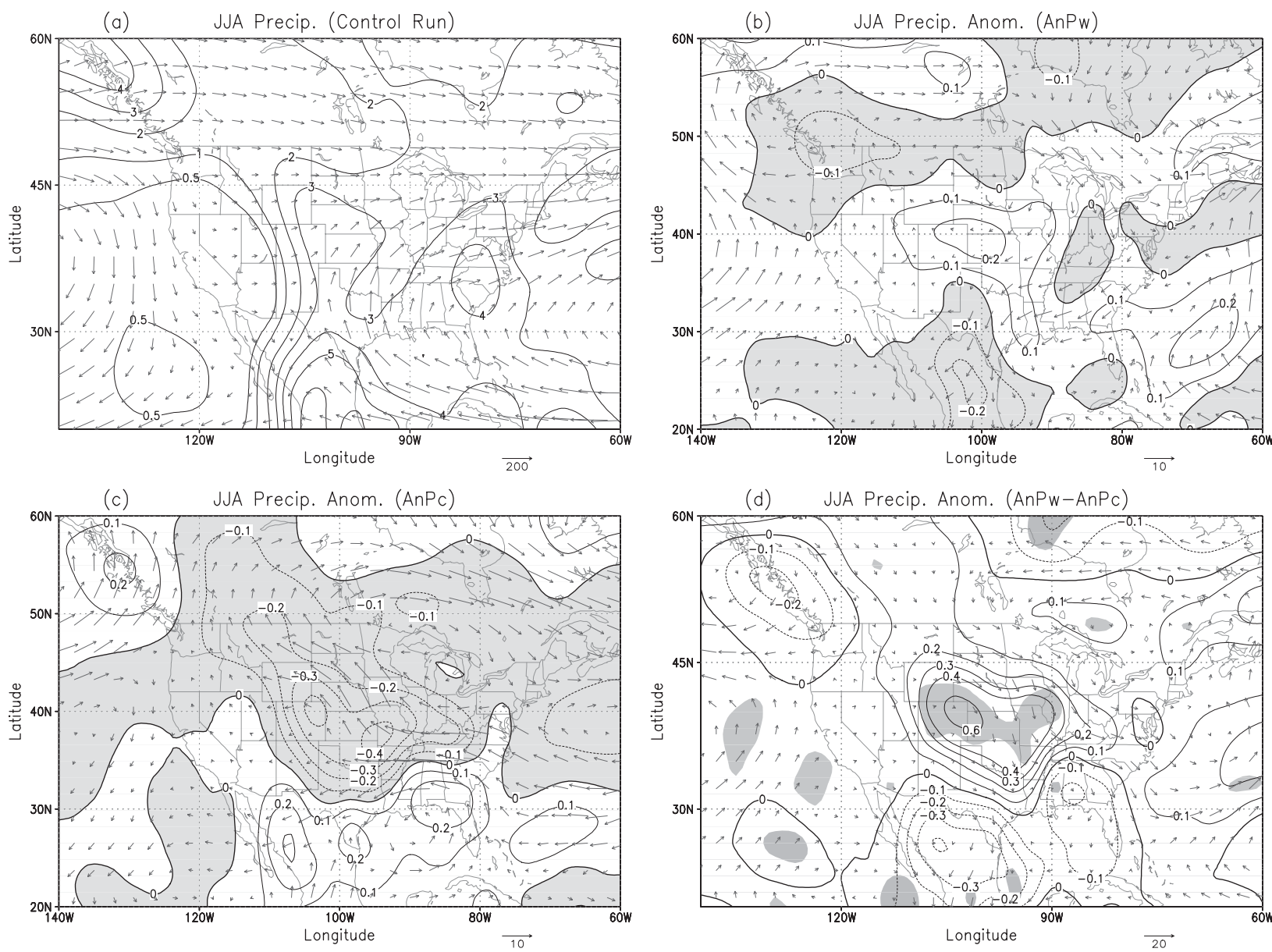

FIG. 8. (a) Simulated impact of ENSO on North American summer precipitation ( $\mathrm{mm} \mathrm{day}^{-1}$ ) for control run. (b),(c) Anomalies from the control run averaged for ENSO warm $\left(\mathrm{A}_{n} \mathrm{P}_{\mathrm{w}}\right)$ and cold phase $\left(\mathrm{A}_{\mathrm{n}} \mathrm{P}_{\mathrm{c}}\right)$, respectively (negative anomalies are shaded). (d) Differences between (b) and (c). Shadings in (d) indicate the differences in summer precipitation are significant at the $95 \%$ confidence level by the twotailed Student's $t$ test. The arrows in the panels show the 1000-700-hPa moisture flux anomalies $\left(\mathrm{kg} \mathrm{m}^{-1} \mathrm{~s}^{-1}\right)$.

$\left(35^{\circ}-55^{\circ} \mathrm{N}\right)$, especially in the central United States, between El Niño and La Niña during the warm phase of the AMO. Comparing Fig. 9a with Fig. 8b and Fig. 9b with Fig. $8 \mathrm{c}$, we find that the differences between the anomalies in Figs. 9a and 9b are very similar to those between Figs. $8 \mathrm{~b}$ and $8 \mathrm{c}$ driven by ENSO alone. Because the SST effect in the warm phase of the AMO was in the anomalies in Figs. 9a and 9b, this similarity indicates that ENSO strongly modifies the AMO effect in midlatitude North America and dominates its precipitation anomalies. Further comparisons of the results in Figs. 9a and 9b with that in Fig. 9c, which was driven by the AMO warm phase SST alone, show distinct features in precipitation anomalies in Figs. 9a and 9b different from that in Fig. 9c. This dissimilarity confirms that ENSO plays a more important role than the AMO in regional precipitation anomalies in midlatitude North America.

The same results occur for La Niña during the cold phase of the AMO. As shown in Fig. 9e, in La Niña years during the cold phase of the AMO, negative precipitation anomalies spread through most of midlatitude North America. However, in El Niño years during the cold phase of the AMO a somewhat unexpected result is shown in Fig. 9d. The precipitation anomaly during El Niño is not opposite to that in La Niña in the same cold phase of the AMO (Fig. 9e). In addition, the anomaly pattern is quite different from that driven by El Niño alone (Fig. 8b) but resembles some signatures of the AMOforced anomalies (Fig. 9f). For example, the strong positive anomaly in precipitation centered in the central United States forced by El Niño in Fig. $8 b$ is absent in Fig. 9d. This result is counterintuitive because if individual El Niño or the AMO cold phase is to force positive precipitation anomalies in the central United States, a superimposition of the two may be anticipated to result in larger positive anomalies. The result opposite to this expectation may question the previously proposed quasi-linear interrelationship between ENSO and the AMO in their 

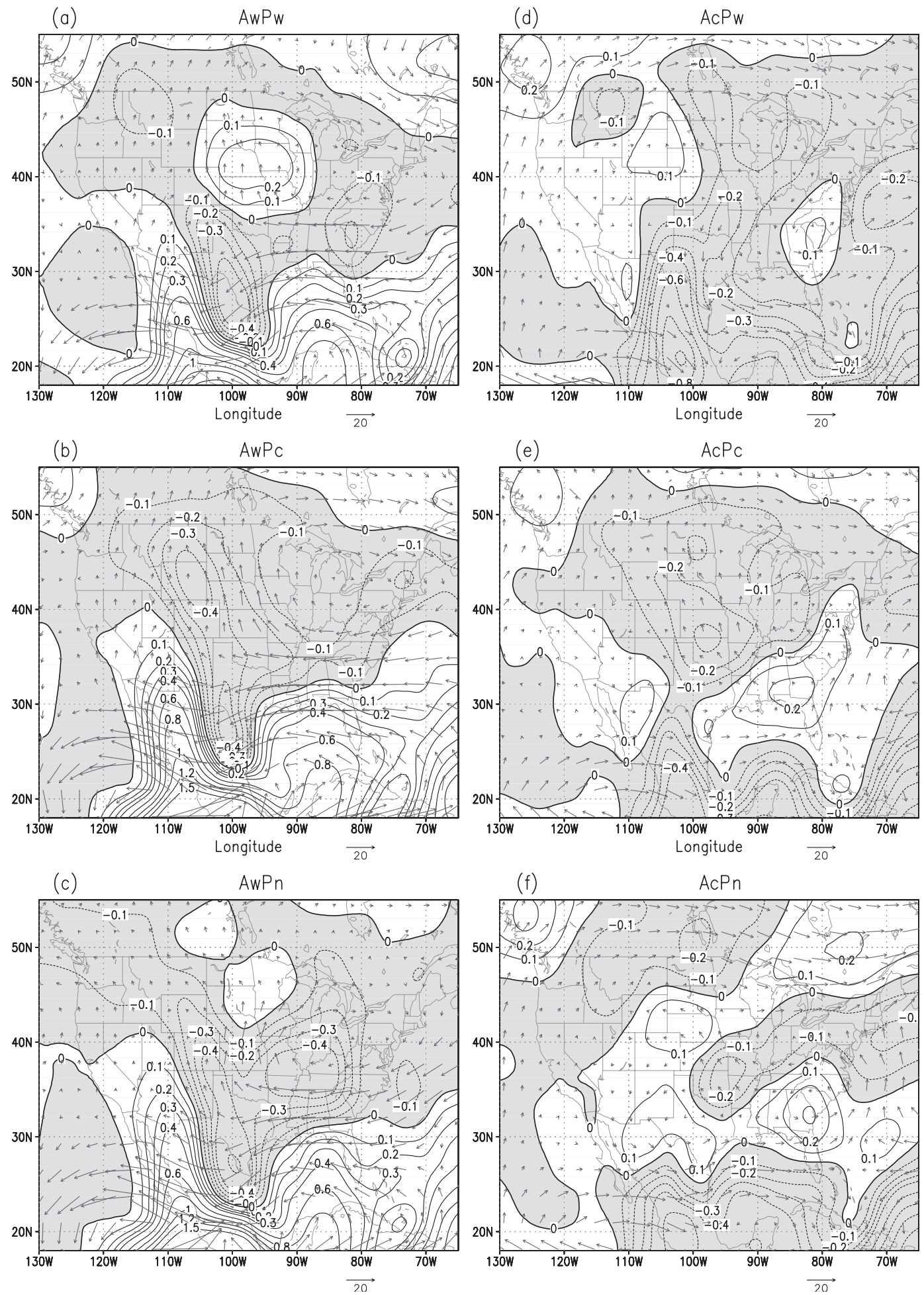

FIG. 9. Simulated JJA precipitation anomalies $\left(\mathrm{mm} \mathrm{day}^{-1}\right)$ for indicated forcing conditions (negatives are shaded). The arrows in the panels show the 1000-700-hPa moisture flux anomalies $\left(\mathrm{kg} \mathrm{m}^{-1} \mathrm{~s}^{-1}\right)$. 
effects on the summertime precipitation. As we will elaborate in the next subsection, this result is an overshooting outcome of the linear superposition of the effects of the AMO and ENSO.

To summarize, the AMO has dominated the summertime precipitation anomaly pattern in the tropical and subtropical regions where ENSO modifications to the AMO effect are shown by adding interannual variations in the intensity of the anomalies without altering the spatial pattern. As a result, summertime precipitation in subtropical North America has a distinct multidecadal variation following the AMO. In midlatitude North America, ENSO plays a stronger role influencing the summertime precipitation variations and the AMO effects are shown in background intensity of the variations. Less precipitation is anticipated during La Niña across the region and more during El Niño, except in the cold phase of the AMO when interactions of ENSO and the AMO may suppress their individual effects and result in neutral or even slightly negative anomalies in summertime precipitation. As a result, precipitation in the midlatitude region has strong interannual variations following the ENSO cycle with their intensity varying at multidecadal time scale following the AMO. The driest condition in North America occurs in La Niña during the warm phase of the AMO, a result supporting the notion that the cold tropical Pacific and warm North Atlantic are a combination ideal for severe droughts in North America (Feng et al. 2008; Schubert et al. 2009; Mo et al. 2009; Nigam et al. 2011).

\section{d. Mechanisms}

In these simulations, the atmospheric circulation anomalies driven by the AMO and ENSO are the primary sources for development of precipitation anomalies in North America. As previously shown ( $\mathrm{Hu}$ et al. 2011), during the cold phase of the AMO, the NASH pressure system enhanced and shifted its center westward by nearly $20^{\circ}$. The western portion of the NASH is extended considerably in the meridional direction, and North America is effectively under the influence of the western part of this enhanced high pressure system. Positive SLP anomalies develop in North America. On the other hand, during the AMO warm phase, the NASH contracts substantially as its center shifts eastward by about $20^{\circ}$. Strong negative SLP anomalies occur over the subtropical North Atlantic, extending to the eastern subtropical Pacific. Negative SLP anomalies develop over most of North America. These modeled anomalies in association with the AMO are consistent with the observations (Hu and Feng 2008; Curtis 2008).

Similar low-level circulation anomalies develop during El Niño and La Niña. As previously discussed, most of midlatitude North America has a positive SLP anomaly during El Niño (Fig. 2b) and reversed anomaly during La Niña (Fig. 2c). While the causes-forcings differ, the resulting positive SLP anomalies in North America are similar in the AMO cold phase and in El Niño. Negative SLP anomalies in North America occurred in the AMO warm phase and in La Niña. Because above-average summertime precipitation has been observed in North America during the cold phase of the AMO alone (Fig. 9f) and also during El Niño alone (Fig. 8b), we postulate that adequate positive anomalies in SLP, and in lower-troposphere pressure, in North America during summer cause above-average precipitation, particularly in the midlatitude North America, and negative anomalies cause below-average precipitation.

The causal effects of the circulation anomalies on precipitation development from the AMO have been studied and described in $\mathrm{Hu}$ et al. (2011), so here we focus on causal effects of ENSO and the combined effects of ENSO and the AMO. During ENSO, two primary processes in the lower to upper troposphere contribute to the anomalies in atmospheric circulation and precipitation. In El Niño, the positive SLP anomalies over the United States, shown in Fig. 2b, indicate anomalous easterly and southeasterly winds in the southern half of the United States. These anomalous winds facilitate moisture transport to the south-central and central United States from the south and the east. In contrast, during La Niña (Fig. 2c), anomalous westerly and southwesterly winds from the south and southwestern United States, associated with the negative pressure anomalies centered in the central United States, advect dry air from the desert southwest United States and the Mexican Plateau to the central and southcentral United States. This circulation anomaly not only interrupts the low-level moisture flow from the Gulf of Mexico to midlatitude North America but also acts directly to dry the region by increasing surface evaporation (Veres and $\mathrm{Hu}$ 2012). These contrasting differences are also shown in the $850-\mathrm{hPa}$ mass and wind anomalies (figure not shown).

In the mid- and upper troposphere $(500-200 \mathrm{hPa}$, see Fig. 5), the mass and wind anomalies also differ between El Niño and La Niña, contributing to their different effects in precipitation. In El Niño (Fig. 5b), positive pressure anomalies persist over North America. There are two centers of positive pressure anomalies: a much stronger one over south-central Canada and a weak one off the west coast of Mexico (the weak center over the eastern subtropical Pacific is more clearly shown at $500 \mathrm{hPa}$ ). There are negative pressure anomalies off the west coast of North America and also along the eastern 
contiguous United States. This particular distribution in the pressure anomalies during El Niño creates a deformation field with its axis from northwest to the southeast across the United States. In this deformation field, air mass from the northeast collides with air masses from the southwest, and they diverge along the frontal zone off the southeastern United States. This off-land flow anomaly may have been a major cause for precipitation deficits in the southeastern United States (e.g., Florida) during El Niño events.

A different pattern in the upper-troposphere pressure anomaly develops in La Niña periods. As shown in Fig. $5 \mathrm{c}$, there is a broad region of positive pressure anomalies spreading across the mid- and high latitudes in North America with a strong center over the Great Lakes area. South of this zonal stretch of high pressure anomalies are low pressure anomalies from the subtropical and tropical Pacific to the Atlantic. This pattern of pressure anomalies suggests one large air mass over most of North America during La Niña, in contrast to the deformation field and frontal zone developed during El Niño. These contrasts in pressure and wind anomalies in the mid- and upper troposphere between El Niño and La Niña resemble the features in the cold and warm phases of the AMO (see Figs. 7c and 7d in $\mathrm{Hu}$ et al. 2011), suggesting that processes of similar nature may have been driven by these different SST forcings.

With concurrent forcing of ENSO and the AMO, for example, El Niño or La Niña occurring during warm or cold phase of the AMO, circulation and precipitation anomalies differ from those driven by ENSO alone. As we have previously shown in precipitation variations, these anomaly fields indicate primarily a linear interrelationship of the circulations driven by individual forcing of ENSO and the AMO. In addition, this quasilinear relationship varies with latitude. In the subtropical region a rather uniform effect of ENSO only influences the strength of circulation and precipitation anomalies driven by the AMO. In the midlatitudes of North America, large wave patterns in circulation anomalies driven by ENSO, shown clearly in Figs. 5b-d, strongly modify the AMO effect and dominate the interannual variation in precipitation.

A particular result that may enhance the notion of the quasi-linear relationship between the ENSO and the AMO in midlatitude North America is shown in El Niño during the cold phase of the AMO. As shown in Fig. 9d, in such a situation the summertime precipitation in North America is lower than that in either El Niño (Fig. 8b) or in the cold phase of the AMO (Fig. 9f). The reduced precipitation in this case may be attributed to two circulation anomaly features. First, the superposition of the high pressure anomalies driven by individual forcing from the warm SST anomalies in the eastern tropical Pacific during El Niño and those driven by the cold SST anomalies in the North Atlantic in the cold phase of the AMO results in amplified high pressure anomalies in the midlatitude North America. The amplified pressure anomalies in the lower troposphere can be seen by comparing the results shown in Figs. 2 and 4 . The positive SLP anomalies in El Niño during the cold phase of the AMO (Fig. 4a) are much stronger than those in either the cold phase of the AMO (Fig. 4d) or El Niño alone (Fig. 2b). (A similar result also was found in $850 \mathrm{hPa}$, not shown here.) The strong high pressure anomalies in turn strengthen the low-level divergence, limiting precipitation development. Second, the different interrelationship of El Niño and the cold phase of the AMO between the midlatitude and the subtropics destroys the deformation field, which would develop during El Niño or the cold phase of the AMO alone (Fig. 5b). As previously discussed, this deformation field in either El Niño or in the cold phase of the AMO has played an essential role for above-average precipitation in North America. Without this mechanism, precipitation decreases.

A similar superposition but of negative SLP anomalies occurs in La Niña during the warm phase of the AMO. In such case, the La Niña forcing amplifies negative SLP anomalies driven by the warm phase of the AMO and also makes them expand further into the lower latitudes (Fig. 3b). In a way similar to that described in Hu et al. (2011), the warmer and dryer mass of continental origin weakens development of summertime precipitation in North America, yielding the largest negative anomalies in summertime precipitation, and driest conditions in North America, among the interrelations between ENSO and the AMO (Fig. 9b).

A more quantitative elaboration of the quasi-linear relationship of the circulation anomalies driven by the AMO and the ENSO and resulting precipitation changes is summarized in Table 1.

These various interrelationships in different phases of the ENSO and the AMO and related summertime precipitation anomalies suggest different superposition of atmospheric disturbances in North America driven by the SST anomalies associated with ENSO and the AMO. A plausible explanation of these disturbances and their interrelationships is the following. As suggested in observational and theoretical studies (e.g., Wallace and Gutzler 1981; Hoskins and Karoly 1981), the SST anomalies associated with El Niño excite Rossby waves propagating toward the east in the Pacific-North America (PNA) wave pattern. These waves usually have a wavelength of a few thousand kilometers. Meanwhile, in the cold or warm phase of the AMO the North Atlantic basin-scale SST anomalies excite atmospheric circulation 
TABLE 1. Averaged JJA SLP anomaly $\left(\mathrm{SLP}^{\prime}\right)$ and precipitation anomaly $\left(\operatorname{Pr}^{\prime}\right)$ for the U.S. Great Plains $\left(30^{\circ}-50^{\circ} \mathrm{N}, 90^{\circ}-110^{\circ} \mathrm{W}\right)$ simulated by different model experiments. (We use this region as an example to elaborate the quasi-linear relationship, and note that when averaged in this region there was a reduction in precipitation in the AMO cold phase, see Fig. 9f.) The asterisk by an anomaly indicates it was significant at the $95 \%$ confidence level by the twotailed $t$ test. The "Ctl" is for Control run. The quasi-linear interrelationship of the circulation anomalies driven jointly by the AMO and ENSO and related precipitation anomalies is shown by the results that the SLP from the joint AMO-ENSO experiments, for example, $\mathrm{A}_{\mathrm{w}} \mathrm{P}_{\mathrm{c}}-\mathrm{Ctl}$, assume a quasi-arithmetic relationship of the anomalies driven by the AMO and ENSO alone. In addition, the third set of the experiments shows that the superimposition of the positive anomalies induced by the cold phase of the AMO and El Niño created a large positive SLP anomaly $(+0.65 \times 100 \mathrm{~Pa})$, which in turn enhanced lower-troposphere divergence and resulted in a decrease in precipitation. $\mathrm{A}_{w} \mathrm{P}_{n}-\mathrm{Ctl}$ (warm $\mathrm{AMO}$ ) and $\mathrm{A}_{\mathrm{c}} \mathrm{P}_{\mathrm{n}}-\mathrm{Ctl}$ (cold AMO) are repeated for easier comparison of the ENSO effects.

\begin{tabular}{lcc}
\hline \hline \multicolumn{1}{c}{ Model experiments } & SLP' $^{\prime}(\times 100 \mathrm{~Pa})$ & $\operatorname{Pr}^{\prime}\left(\mathrm{mm} \mathrm{day}^{-1}\right)$ \\
\hline $\mathrm{A}_{\mathrm{w}} \mathrm{P}_{\mathrm{n}}-\mathrm{Ctl}$ (warm AMO) & $-0.58^{*}$ & -0.029 \\
$\mathrm{~A}_{\mathrm{n}} \mathrm{P}_{\mathrm{w}}-\mathrm{Ctl}$ (El Niño) & +0.20 & +0.070 \\
$\mathrm{~A}_{\mathrm{w}} \mathrm{P}_{\mathrm{w}}-\mathrm{Ctl}$ (El Niño in & $-0.45^{*}$ & +0.002 \\
$\quad$ warm AMO) & & \\
& & \\
$\mathrm{A}_{\mathrm{w}} \mathrm{P}_{\mathrm{n}}-\mathrm{Ctl}$ (warm AMO) & $-0.58^{*}$ & -0.029 \\
$\mathrm{~A}_{\mathrm{n}} \mathrm{P}_{\mathrm{c}}-\mathrm{Ctl}$ (La Niña) & -0.16 & $-0.190^{*}$ \\
$\mathrm{~A}_{\mathrm{w}} \mathrm{P}_{\mathrm{c}}-\mathrm{Ctl}$ (La Niña & $-0.70^{*}$ & $-0.201^{*}$ \\
in warm AMO) & & \\
& & -0.083 \\
$\mathrm{~A}_{\mathrm{c}} \mathrm{P}_{\mathrm{n}}-\mathrm{Ctl}$ (cold AMO) & $+0.51^{*}$ & +0.070 \\
$\mathrm{~A}_{\mathrm{n}} \mathrm{P}_{\mathrm{w}}-\mathrm{Ctl}$ (El Niño) & +0.20 & -0.046 \\
$\mathrm{~A}_{\mathrm{c}} \mathrm{P}_{\mathrm{w}}-\mathrm{Ctl}$ (El Niño & $+0.65^{*}$ & \\
in cold AMO) & & -0.083 \\
& & $-0.190^{*}$ \\
$\mathrm{~A}_{\mathrm{c}} \mathrm{P}_{\mathrm{n}}-\mathrm{Ctl}$ (cold AMO) & $+0.51^{*}$ & $-0.138^{*}$ \\
$\mathrm{~A}_{\mathrm{n}} \mathrm{P}_{\mathrm{c}}-\mathrm{Ctl}$ (La Niña) & -0.16 & \\
$\mathrm{~A}_{\mathrm{c}} \mathrm{P}_{\mathrm{c}}-\mathrm{Ctl}$ (La Niña & $+0.47^{*}$ & \\
in cold AMO) & & \\
\hline
\end{tabular}

anomalies of planetary scales. These planetary-scale waves in the atmosphere would retrograde owing to the $\beta$ effect (Holton 2004) and create an upstream effect of the AMO in North America. These retrograding planetary waves were observable in the AMO-driven circulation anomalies from the simulations shown in $\mathrm{Hu}$ et al. (2011, see their Fig. 8). These AMO- and ENSO-driven waves result in different precipitation anomaly distributions in North America depending on their phase relationships (superposition).

While this postulation requires further evaluation, it is supported by some observations. When the effect of ENSO on summertime precipitation in North America is removed by statistical filtering, the observed correlations of the filtered precipitation, and the AMO-related SST anomalies are similar to the AMO-driven precipitation anomalies simulated by the NCAR CAM3.1 (Hu et al.
2011, see their Fig. 3). Moreover, when the AMO effect is removed the ENSO-driven summertime precipitation anomalies (Figs. 8b and 8c) are similar to the observed effects of ENSO on summertime precipitation in North America (Hu and Feng 2001). These results strengthen the notion of a strong quasi-linear relationship of ENSO and the AMO in their joint impacts on North American summertime circulation and precipitation.

\section{Summary and concluding remarks}

To further understand interannual and multidecadal time-scale variations in summertime precipitation in North America we have extended our previous study of the AMO-driven variations in circulation and precipitation (Hu et al. 2011) and included ENSO forcing. Major results show strong modifications of the equatorial Pacific SST anomalies associated with El Niño and La Niña on circulation variations driven by the AMO, creating interannual fluctuations that are superimposed on the AMO-driven multidecadal time-scale background anomalies in summertime precipitation in North America. Furthermore, these modifications differ considerably between the subtropics and the mid- and highlatitude region. In the subtropics, the ENSO-driven variations in precipitation are fairly uniform longitudinally and thus only add amplitude fluctuations to the precipitation anomaly pattern driven by the AMO. Consequently, precipitation variation in the subtropics is primarily driven by the AMO and has a dominant mode at the multidecadal time scale. This result is consistent with the finding that the AMO has a strong signal and dominant influence in the tropical and subtropical regions in the western hemisphere (e.g., Seager et al. 2005; Knight et al. 2006).

In the mid- and high latitudes, the ENSO-forced wave anomalies in the atmosphere, for example, the PNA pattern, strongly influence the circulation anomalies driven by the AMO and associated planetary-scale waves retrograding westward from the North Atlantic basin. Because these ENSO- and AMO-driven waves originate from sources of different nature they interact rather mechanically, in contrast to waves of dispersive nature. The waves superimpose their effects in midlatitude North America. Moreover, because the amplitudes of the ENSO-forced shorter waves are larger in amplitude than that of the AMO-driven planetaryscale waves, the ENSO force strongly influences the outcome variation in the circulation and precipitation in midlatitude North America. As a result, summertime precipitation in North America has strong regional pattern with a distinctive interannual time scale following the ENSO cycle (Hu and Feng 2001). The AMO 
also plays a role, however. Its effect causes an asymmetry in precipitation response to El Niño and La Niña. That is, summertime precipitation has a much larger positive anomaly in El Niño years occurring during the warm phase of the AMO than the nearly null response in El Niño occurring during the cold phase of the AMO.

An interpretation of the utterly different effects of El Niño on precipitation in different phases of the AMO is that both the North Atlantic SST anomalies in the cold phase of the AMO and the equatorial Pacific SST anomalies during El Niño cause positive pressure anomalies in the lower troposphere in midlatitude North America. While moderate positive pressure anomalies from either one of these forcings would enhance the moisture flow from the east and the south, their superimposed effect results in amplified strong positive pressure anomalies that set off strong low-level divergence in midlatitude North America and suppress precipitation development. On the other hand, during the warm phase of the AMO, the negative pressure anomalies are offset by strong positive anomalies driven by El Niño. The net effect of this superposition is suitable positive low-level pressure anomalies, which enhance moisture transport and precipitation development.

The driest condition in North America occurs during La Niña in the warm phase of the AMO. The negative pressure anomalies driven by the warmer SST during the warm phase of the AMO are amplified by La Niña forcing. The amplified negative pressure anomalies in the lower troposphere force strong flows from the southwestern United States and Mexican Plateau to central North America, severely suppressing summertime precipitation. ${ }^{2}$

This result that the driest summer condition in North America occurs during La Niña in the warm phase of the AMO is consistent with that found in Mo et al. (2009) in a similar study. However, they also suggest that the cold phase of the AMO consistently produces above-average precipitation during El Niño, a result that is different from what we showed previously in this report. This difference might have resulted from the difference in analyses between these two studies. In Mo et al. (2009) all four seasons were included in analyses of effects of the AMO and ENSO. Only the summer season effect of these forcings is considered in this current study, primarily because the AMO has a profound effect

\footnotetext{
${ }^{2}$ The observational records have shown that the severe droughts in summers of 2010 and 2011 in the southern United States (e.g., droughts and frequent dust storms in Arizona and wildfires in Texas) occurred during back-to-back La Niñas in an on-going warm phase of the AMO.
}

concentrated in boreal summer (Hu and Feng 2008). Because El Niño has a strong effect on winter as well as other seasons' precipitation variation in North America, when all seasons were considered the El Niño effect would become dominant in precipitation response to these forcings, particularly in the midlatitude regions. Further investigations are necessary to clarify these differences to gain a better understanding of the effects of ENSO and the AMO.

While differences remain, results from this and previous studies, particularly of the CLIVAR Drought Working Group, show changes in ENSO effects on the North American summertime precipitation variations in different phases of the AMO. These changing effects of ENSO describe a role of the AMO in regulating the interannual variations associated with ENSO at a multidecadal time scale. Thus, the identified potential mechanisms for the AMO-ENSO influences on summertime precipitation variations should be useful for us to improve predictions of precipitation in North America at interannual to multidecadal time scales.

The results of this study were obtained without taking the effects of the SST anomalies in the mid- and highlatitude North Pacific Ocean associated with the Pacific decadal oscillation (PDO) into consideration. Additionally, because invariant SST anomalies were used to describe El Niño and La Niña and the AMO, interactions of SST variations in ENSO and the AMO were excluded. While the linear interrelationships of the PDO, AMO, and ENSO and their combined effects on interannual to multidecadal time-scale circulation and precipitation anomalies in North America are currently examined in a separate analysis, the ultimate challenge to our understanding of the effects of these boundary forcings is on how they are interacting and how their interactions are changing the relationship described in this study and affecting the atmospheric circulation and precipitation in North America. As noted, El Niño-La Niña has a strong signal in the North Atlantic SST variation and the AMO also has an extended signal in the North Pacific (e.g., Dong et al. 2006; D'Orgeville and Peltier 2007; DelSole et al. 2010; Wang et al. 2011). These cross-basin signals would likely create strong nonlinear interactions and feedbacks among these forcings and influence atmospheric circulation and precipitation. The effects from the simple settings of model experiments presented in this study provide a foundation for further studies to gain an understanding of such nonlinear interactions and effects of these forcing.

Acknowledgments. We thank Dr. R. J. Oglesby for facilitating computing resources. The comments and suggestions from three anonymous reviewers, the editor 
Dr. Kerry H. Cook, and Dr. Robert F. Diffendal of the UNL helped improve this manuscript and are greatly appreciated. The simulations were made at the computational facilities of the National Center for Computational Services at Oak Ridge National Laboratory. This research has been supported by NOAA Grant NA09OAR4310188 and NSF Grant AGS-1103316 to the University of Nebraska at Lincoln and by the USDA Cooperative Research Project NEB-38-088.

\section{REFERENCES}

Bjerknes, J., 1964: Atlantic air-sea interaction. Advances in Geophysics, Vol. 10, Academic Press, 1-82.

Collins, W. D., and Coauthors, 2006: The formulation and atmospheric simulation of the Community Atmosphere Model version 3 (CAM3). J. Climate, 19, 2144-2161.

Curtis, S., 2008: The Atlantic multidecadal oscillation and extreme daily precipitation over the US and Mexico during the hurricane season. Climate Dyn., 30, 343-351.

DelSole, T., M. K. Tippett, and J. Shukla, 2010: A significant component of unforced multidecadal variability in the recent acceleration of global warming. J. Climate, 24, 909-926.

Dong, B., R. T. Sutton, and A. A. Scaife, 2006: Multidecadal modulation of El Niño-Southern Oscillation (ENSO) variance by Atlantic Ocean sea surface temperatures. Geophys. Res. Lett., 33, L08705, doi:10.1029/2006GL025766.

D'Orgeville, M., and W. R. Peltier, 2007: On the Pacific decadal oscillation and the Atlantic multidecadal oscillation: Might they be related? Geophys. Res. Lett., 34, L23705, doi:10.1029/ 2007GL031584.

Enfield, D. B., A. M. Mestas-Nunez, and P. J. Trimble, 2001: The Atlantic multidecadal oscillation and its relation to rainfall and river flows in the continental U.S. Geophys. Res. Lett., 28, 2077-2080.

Feng, S., R. J. Oglesby, C. M. Rowe, D. B. Loope, and Q. Hu, 2008: Atlantic and Pacific SST influences on Medieval drought in North America simulated by the Community Atmospheric Model. J. Geophys. Res., 113, D11101, doi:10.1029/2007JD009347.

—, Q. Hu, and R. J. Oglesby, 2011: Influence of Atlantic sea surface temperature on persistent drought in North America. Climate Dyn., 37, 569-586.

Frankignoul, C., 1985: Sea surface temperature anomalies, planetary waves and air-sea feedback in the middle latitudes. Rev. Geophys., 23, 357-390.

Griffies, S. M., and K. Bryan, 1997: Predictability of North Atlantic multidecadal climate variability. Science, 275, 181-184.

Holton, R. J., 2004: Introduction to Dynamic Meteorology. 4th ed. Academic Press, 535 pp.

Hoskins, B. J., and D. J. Karoly, 1981: The steady linear response of a spherical atmosphere to thermal and orographic forcing. J. Atmos. Sci., 38, 1179-1196.

$\mathrm{Hu}$, Q., and S. Feng, 2001: Variations of teleconnection of ENSO and interannual variation in summer rainfall in the central United States. J. Climate, 14, 2469-2480.

— monsoon regimes and the Atlantic multidecadal oscillation. J. Climate, 21, 2373-2383.

,-- , and R. J. Oglesby, 2011: Variations in North American summer precipitation driven by the Atlantic multidecadal oscillation. J. Climate, 24, 5555-5570.
Hurrell, J. W., 1995: Decadal trends in the North Atlantic Oscillation: Regional temperatures and precipitation. Science, 269, 676-679.

— J. J. Hack, D. She, J. M. Caron, and J. Rosinski, 2008: A new sea surface temperature and sea ice boundary dataset for the Community Atmosphere Model. J. Climate, 21, 5145-5153.

Kerr, R. A., 2000: A North Atlantic climate pacemaker for the centuries. Science, 288, 1984-1986.

Kitzberger, T., P. M. Brown, E. K. Hayerdahl, T. W. Swetnam, and T. T. Veblen, 2007: Contingent Pacific-Atlantic Ocean influence on multicentury wildfire synchrony over western North America. Proc. Natl. Acad. Sci. USA, 104, 543-548.

Knight, J. R., C. K. Folland, and A. A. Scaife, 2006: Climate impacts of the Atlantic multidecadal oscillation. Geophys. Res. Lett., 33, L17706, doi:10.1029/2006GL026242.

Kushnir, Y., W. A. Robinson, I. Blade, N. M. J. Hall, S. Peng, and R. Sutton, 2002: Atmospheric GCM responses to extratropical SST anomalies: Synthesis and evaluation. J. Climate, 15, 2233 2256.

—, R. Seager, M. Ting, N. Naik, and J. Nakamura, 2010: Mechanisms of tropical Atlantic SST influence on North American precipitation variability. J. Climate, 23, 5610-5627.

Latif, M., and T. P. Barnett, 1994: Causes of decadal climate variability over the North Pacific and North America. Science, 266, 634-637.

— Pacific and North America: Dynamics and predictability. J. Climate, 9, 2407-2423.

Lau, N. C., 1985: Modeling the seasonal dependence of the atmospheric response to observed El Niños in 1962-76. Mon. Wea. Rev., 113, 1970-1996.

_ of tropical and extratropical SST anomalies in the variability of the global atmosphere-ocean system. J. Climate, 7, 11841207.

— linking tropical Pacific ENSO events to extratropical SST anomalies. J. Climate, 9, 2036-2057.

Lu, R., and B. Dong, 2005: Impact of Atlantic sea surface temperature anomalies on the summer climate in the western North Pacific during 1997-1998. J. Geophys. Res., 110, D16102, doi:10.1029/2004JD005676.

McCabe, G. J., M. A. Palecki, and J. L. Betancourt, 2004: Pacific and Atlantic Ocean influences on multidecadal drought frequency in the United States. Proc. Natl. Acad. Sci. USA, 101, 4136-4141, doi:10.1073/pnas.0306738101.

Meehl, G. A., and Coauthors, 2009: Decadal prediction: Can it be skillful? Bull. Amer. Meteor. Soc., 90, 1467-1485.

Mestas-Nunez, A., and D. B. Enfield, 1999: Rotated global modes of non-ENSO sea surface temperature variability. J. Climate, 12, 2734-2746.

Mo, K. C., J. E. Schemm, and S.-H. Yoo, 2009: Influence of ENSO and the Atlantic multidecadal oscillation on drought over the United States. J. Climate, 22, 5962-5982.

Namias, J., 1959: Recent seasonal interaction between North Pacific waters and the overlying atmospheric circulation. J. Geophys. Res., 64, 631-646.

_, 1965: Macroscopic association between monthly mean sea surface temperature and overlying winds. J. Geophys. Res., 70, 2307-2318.

_ 1969: Seasonal interactions between the North Pacific Ocean and the atmosphere during the 1960s. Mon. Wea. Rev., 97, 173-192. 
_ X. Yuan, and D. R. Cayan, 1988: Persistence of North Pacific sea surface temperature and atmospheric flow patterns. J. Climate, 1, 682-703.

Nigam, S., B. Guan, and A. Ruiz-Barradas, 2011: Key role of the Atlantic multidecadal oscillation in 20th century drought and wet periods over the Great Plains. Geophys. Res. Lett., 38, L16713, doi:10.1029/2011GL048650.

Palmer, T. N., and Z. Sun, 1985: A modeling and observational study of the relationship between sea-surface temperature in the northwest Atlantic and the atmospheric general-circulation. Quart. J. Roy. Meteor. Soc., 111, 947-975.

Schubert, S., and Coauthors, 2009: A U.S. CLIVAR project to assess and compare the responses of global climate models to drought-related SST forcing patterns: Overview and results. J. Climate, 22, 5251-5272.

Seager, R., Y. Kushnir, M. Visbeck, N. Naik, J. Miller, G. Krahmann, and H. Cullen, 2000: Causes of Atlantic Ocean climate variability between 1958 and 1998. J. Climate, 13, 2845-2862.

,,-- C. Herweijer, N. Naik, and J. Velez, 2005: Modeling of tropical forcing of persistent droughts and pluvial over western North America: 1856-2000. J. Climate, 18, 4065-4088.

Sutton, R. T., and D. L. R. Hodson, 2005: Atlantic Ocean forcing of North American and European summer climate. Science, 309, 115-118.

_ , and _ 2007: Climate response to basin-scale warming and cooling of the North Atlantic Ocean. J. Climate, 20, 891-907.

Ting, M., and S. Peng, 1995: Dynamics of early and middle winter atmospheric responses to northwest Atlantic SST anomalies. J. Climate, 8, 2239-2254.
—_, and H. Wang, 1997: Summertime U.S. precipitation variability and its relation to Pacific sea surface temperature. J. Climate, 10, 1853-1873.

Trenberth, K. E., and G. W. Branstator, 1992: Issues in establishing causes of the 1988 drought over North America. J. Climate, 5, 159-172.

— - and V. J. Guillemot, 1996: Physical processes in 1988 drought and 1993 floods in North America. J. Climate, 9, 12881298.

—, G. W. Branstator, D. Karoly, A. Kumar, N. C. Lau, and C. Ropelewski, 1998: Progress during TOGA in understanding and modeling global teleconnections associated with tropical sea surface temperatures. J. Geophys. Res., 103 (C7), 14 29114324.

Venzke, S., M. R. Allen, R. T. Sutton, and D. P. Rowell, 1999: The atmospheric response over the North Atlantic to decadal changes in sea surface temperature. J. Climate, 12, 2562-2584.

Veres, M. C., and Q. Hu, 2012: AMO-forced regional processes affecting summertime precipitation variations in the central United States. J. Climate, in press.

Wallace, J. M., and D. S. Gutzler, 1981: Teleconnections in the geopotential height field during the Northern Hemisphere winter. Mon. Wea. Rev., 109, 784-812.

Wang, C., D. B. Enfield, S. K. Lee, and C. W. Landsea, 2006: Influences of the Atlantic warm pool on Western Hemisphere summer rainfall and Atlantic hurricanes. J. Climate, 19, 30113028.

Wang, X., C. Wang, W. Zhou, D. Wang, and J. Song, 2011: Teleconnected influence of North Atlantic sea surface temperature on the El Niño onset. Climate Dyn., 37, 663-676. 